\title{
MUJERES Y MERITOCRACIA. RAÍCES HISTÓRICAS DE UN PARADIGMA Y POSIBILIDADES ACTUALES DE TRANSFORMACIÓN
}

\author{
Women and Meritocracy. \\ Historical Roots of a Paradigm and Current Possibilities of Transformation
}

\author{
Rosa María Almansa Pérez \\ rosamaria.almansa@unir.net \\ Universidad Internacional de La Rioja (UNIR). España
}

Fecha de recepción: 30/10/2019

Fecha de aceptación: 03/05/2020

RESUMEN: El trabajo investiga acerca de las posibilidades de que una mayoría de mujeres contribuya a formar un sujeto social de transformación del modelo competitivo-meritocrático vigente. Se parte de la hipótesis de que la valoración meritocrática se encuentra en la base de toda forma histórica de desigualdad social, incluyendo la de género. Un planteamiento que se confirma a través del repaso a la atribución de méritos a las clases dominantes desde los inicios de la estratificación social hasta la edad contemporánea.

Aunque con esta última las mujeres se van incorporando, gracias a la conquista de derechos, a los mecanismos de competencia propios de nuestras sociedades, un gran número continúa encontrándose al margen de los mismos o en inferioridad de condiciones para competir. La economía feminista y el ecofeminismo han revelado que esto se debe, en parte, a que una mayoría de mujeres continúa volcada en trabajos de cuidados y reproducción de la vida. Estos quedan fuera de las dinámicas de competición meritocrática y de revalorización permanente del capital. Por ello mismo, tales enfoques los integran en las alternativas a la actual crisis ecológica, económica y social. Además, este tipo de actividades realizadas por mujeres puede conectarse con las nociones de trabajo libre o autorrealizado manejadas desde hace mucho tiempo. Nos encontramos con ello con la posibilidad de que las mujeres puedan formar parte importante de un proceso de transformación del actual paradigma legitimador de las desigualdades, y que provoca la degradación y destrucción de la vida a todos los niveles.

Palabras clave: mujeres; historia; feminismo; desigualdad social; trabajo libre; cambio social. 
ABSTRACT: The work investigates about the possibilities that a majority of women contribute to form a social subject of transformation of the current competitive-meritocratic model. It is started from the hypothesis that meritocratic valuation is at the base of all historical forms of social inequality, including gender inequality. An approach that is confirmed through a review of the attribution of merits to the dominant classes from the beginning of social stratification to the contemporary age.

Although with the latter, women are becoming incorporated, thanks to the conquest of rights, into the mechanisms of competition that are characteristic of our societies, a large number continue to find themselves on the margins or in inferior conditions to compete. Feminist economics and ecofeminism have revealed that this is due, in part, to the fact that a majority of women continue to be involved in care work and work that reproduces life. These remain outside the dynamics of meritocratic competition and the permanent revaluation of capital. For this reason, such approaches integrate them into the alternatives to the current ecological, economic and social crisis. This type of life's recreation activities can be connected with the notions of good or self-realized work that have long been handled. We find then that women could be an important part of a process of transformation of the current paradigm that legitimizes inequalities, and the degradation and destruction of life at all levels.

KEYWORDS: women; history; feminism; social inequality; good work; Social change.

Sumario: 1. Introducción. 2. La idea de mérito como fuente de legitimación de las desigualdades sociales. Algunos precedentes históricos. 2.1. Mérito y meritocracia: algunas precisiones necesarias. 2.2. El mérito como constante histórica. 3. La era contemporánea y la sanción universal de la idea de mérito. 3.1. Las consecuencias para las mujeres 3.2. La persistencia del elitismo. 4. La situación actual de las mujeres. 5. El trabajo de las mujeres, polo opuesto de la valoración meritocrática. 6 . El trabajo libre, vía de superación de la valoración meritocrática. 7. Conclusiones: Las mujeres como parte de un sujeto posible de cambio social. 8. Referencias bibliográficas.

\section{INTRODUCCIÓN}

Numerosas voces autorizadas vienen poniendo de manifiesto que nos encontramos en un momento histórico de particular agudización de las contradicciones sociales en sentido extenso, así como de las económicas, ecológicas y políticas, entre otras (Bardi, 2014; Beck, 2000, pp. 9-11; Bensaïd, 2010, pp. 15-26 y ss.; Harvey, 2014, p. 228 y ss.; Todd, 1999, pp. 13-15, 28-30, 49-50). Los años setenta y ochenta del siglo Xx suelen tomarse de referente de este cambio de coyuntura, o de alarmante agravamiento de sus síntomas (Alvaredo, Chancel, Piketty, Sáez, y Zucma, 2017, pp. 10-12; Krugman, 2008, pp. 144-146; Meadows, Meadows, Randers, Behrens, 1972; Stiglitz, 2015, p. 109). Pero el proceso se inscribe e interpreta a menudo como una crisis de modelo productivo y de consumo, de crecimiento o, incluso, de valores o civilización (Fernández Durán, 2011, pp. 4-5; Naredo, 2006, pp. 36-38; Observatorio Internacional de la Crisis, Piqueras, Dierckxsens, 2011; Robin, Sörlin, Warde, 2013, pp. 479 y ss.; Sempere, 2008, p. 225 y ss., entre otros).

A partir de la era contemporánea, el sistema de estratificación social de la civilización occidental, basado en criterios abiertamente meritocráticos y en el éxito individual, ha tomado unos perfiles competitivos muy acerados (Beck, Beck-Gernsheim, 
2003, p. 40; Daguerre, 2005, pp. 6-7; Sennett, 2007, p. 129). Semejante sistema competitivo-meritocrático, a pesar de sus supuestas virtudes -en especial la atribución de recompensas en función de méritos objetivos-, no se ha erigido en valladar contra un recrudecimiento sustancial de las desigualdades, a pesar de las predicciones en sentido contrario (Friedman, 1988, pp. 197-198, 206-207). Estas, constatables in extenso y en el interior de las sociedades occidentales en general, cada vez resultan de más difícil sostenimiento y justificación (Bauman, 2014; Hardoon, Ayele, Fuentes-Nieva, 2016; Stiglitz, 2015, 109, 117-118).

Situándose en este contexto, la pretensión de este trabajo es la de contribuir a dilucidar las posibilidades de que pueda formarse un nuevo sujeto social de transformación en profundidad de lo que damos en llamar 'paradigma competitivo-meritocrático'. Un sujeto en el cual pudieran tener un papel clave las mujeres. Esta problemática se estima de importancia porque, entre otras cosas, la toma de conciencia sobre la misma puede resultar decisiva en lo concerniente a su desarrollo o materialización. Para su ponderación se tomarán en cuenta tanto determinadas constantes históricas como características propias de la encrucijada actual.

La principal de tales constantes sería la aludida idea de mérito. Dicha noción entendida como cualidad superior, o conjunto de ellas, que justificarían diferencias relativas en la estratificación social-, aunque presente en todas las épocas históricas, encontraría un nuevo reforzamiento en la era contemporánea (Hobsbawm, 2011a, pp. 189-191). Así pues, el mérito -sostenido en especial por los grupos dominantes- habría constituido una de las principales formas de legitimación de la preeminencia de tales estratos sociales; y en este principio cabría incluir asimismo las formas de dominación y superioridad masculinas sobre las mujeres.

A partir del advenimiento de la contemporaneidad, las mujeres de la órbita occidental se irán incorporando poco a poco, con plenitud formal, a un sistema competitivo-meritocrático conformado plenamente como tal. Dicho acceso se encontrará lastrado por importantes desfases, deficiencias y dificultades, que variarán conforme al ámbito geográfico y la clase social (Hobsbawm, 2011c, p. 227). Aunque se realizan avances sustanciales, en nuestros días persisten situaciones muy extendidas de desigualdad y discriminación más o menos soterradas, y una mayoría de mujeres sigue quedando, de hecho, excluida o en inferioridad de condiciones en los mecanismos de competición por la adquisición de méritos, en especial en niveles medios o altos de la escala social (OIT, 2018, 2019).

En este contexto, las formulaciones teóricas del ecosocialismo, la economía feminista y el ecofeminismo se alejan o muestran críticas con las formulaciones competitivas y meritocráticas al decantarse por posiciones que denominan de «defensa» o "centralidad» de la vida (Herrero, 2010; Mellor, 1996; Mies, Shiva, 1997; Puleo, 2011; Riechmann, 2013). Estas investigaciones vuelven la mirada a formas de trabajo y ocupación que, realizadas tradicionalmente por las mujeres, estarían dotadas de mayor sentido intrínseco; esto es, constituirían, de alguna forma, un 
trabajo de referencia no capitalizado, y, por tanto, una contrapartida al modelo instrumentalizador y mercantilizado de producción y trabajo que se hace omnipresente con la extensión del capitalismo y la contemporaneidad (Polanyi, 1957/2003, pp. 90, 217-218). Conformarían, en este sentido, un polo opuesto a la valoración meritocrática, centrada en la competencia desvalorizadora de los competidores.

Desde el momento en que un referente de trabajo no capitalizado, liberado del corsé competitivo, pueda irse perfilando como alternativa económica, social y humana, cabría también la posibilidad de creación de un sujeto social en torno al mismo. Sobre la naturaleza y trascendencia de un trabajo «libre» o humanizado ya reflexionaron pensadores del pasado, como Aristóteles, Spinoza (Riechmann, 2013, pp. 30, 70), Hegel (Cordua, 1989, p. 115) o el Marx de los Manuscritos (1844/1970, pp. 61-66). Y han continuado haciéndolo autores del presente (Bruni, 2008, p. 60; Dewey, 1916/2004, pp. 258-269; Mies, 1986/2019, pp. 387-392; Schumacher, 1980; Sennett, 2009 o Riechmann, 1998, 28, 27; 2013, entre otros). A esta revalorización pudiera contribuir la propia experiencia vital y de trabajo de muchas mujeres actuales y del pasado.

Este estudio posee un enfoque y tratamiento histórico preponderante, centrado sobre todo en la época contemporánea. Sus resultados son asimismo fruto de la aplicación de conocimientos tomados de disciplinas afines tales como la sociología, la economía, la filosofía y el acervo teórico del feminismo. Las aportaciones de todas ellas han resultado imprescindibles para el tratamiento de un problema complejo que exige de perspectivas interdisciplinares. No se ha pretendido, con todo, realizar un resumen expositivo ni sistemático de diferentes planteamientos teóricos o corrientes en el seno de ninguna de tales áreas.

El artículo se ha estructurado en seis partes fundamentales. Comienza con una argumentación acerca del mérito en tanto que constante histórica, la cual habría servido de baluarte de legitimación de desigualdades sociales y también entre sexos. Ello se ilustra con algunas ejemplificaciones que se estiman significativas. Un segundo punto se dedica al fenómeno de la universalización de la idea de mérito en la era contemporánea y la creciente incorporación de las mujeres a los nuevos cánones impuestos a partir de entonces. Asimismo, se realiza una incursión en el tema de la persistencia y reforzamiento del elitismo meritocrático en las últimas décadas. A continuación, se aborda la perpetuación de la desigualdad y la violencia sexista en el mundo, y el hecho de que la consecución de determinados puestos de responsabilidad o poder ocupados por mujeres se encuentra en correspondencia con su posición previa de preeminencia social y económica. Un cuarto apartado explica en qué sentido los trabajos llevados a cabo, en el pasado y en la actualidad, por una mayoría de mujeres, pudieran ser observados, en determinadas condiciones, como un referente de cuestionamiento de los mecanismos de valorización desigual meritocrática. Se continúa haciendo una referencia a lo que determinados autores (Sennett, 2009, p. 329, o Schumacher, 1980, 1983, 
p. 16) han formulado como trabajo «libre», y en qué sentido pudieran incardinarse en él muchas de las tareas desempeñadas por las mujeres; para terminar articulando unas conclusiones en las que se sintetizan los principales hallazgos del artículo.

\section{LA IDEA DE MÉRITO COMO FUENTE DE LEGITIMACIÓN DE LAS DESIGUALDADES SOCIALES. ALGUNOS PRECEDENTES HISTÓRICOS}

\section{2..1. Mérito y meritocracia: algunas precisiones necesarias}

El sentido actual del término 'meritocracia' fue acuñado a finales de los años cincuenta por el sociólogo Michael Young en su obra satírica The rise of the Meritocracy (1958/1961). En ella, el autor pretendía mostrar los graves riesgos de un sistema que, de forma sistemática, premiaba la inteligencia y nutría a sus élites con aquellos individuos dotados de capacidades supuestamente superiores a la media a través de un sistema escolar selectivo. Uno de los argumentos centrales de lo que pretendía ser una feroz crítica al sistema meritocrático radicaba en que, a pesar de que con él (que sustituía al anterior principio hereditario) las diferencias de clase se acentuaban, tales diferencias eran mejor toleradas que en el pasado. La razón estribaría en que «la estratificación ha estado conforme al principio del mérito, generalmente aceptado a todos los niveles de la sociedad» (p. 123, trad. propia). Las críticas entraban solo a cuestionar, en todo caso, la adecuación de los métodos de selección, no la selección en sí. Para Young, el principal perjuicio consistiría en que, con semejante mecanismo, se condenaría a las clases bajas a la impotencia, dando por descontado que con él se les arrebataría a sus niños más «brillantes».

Este libro contribuyó a otorgar al término 'meritocracia' un sentido negativo. La significación que, con frecuencia, ha venido dándosele a partir de entonces ha sido la de la fosilización, en una élite, de un sistema de privilegios, que quedaría de este modo "cerrado", poco abierto a nuevos "talentos". Esto es, tomaría la acepción de degradación de un sistema de saludable competencia individual, en condiciones de igualdad de oportunidades, por los mejores puestos. Y era este último, en efecto, el ideal liberal clásico que se había impuesto con el ascenso de la burguesía, en tanto que clase crecientemente dominante en Europa, sobre todo a partir de comienzos del siglo XIX (Hobsbawm, 2011a, pp. 187-200). Un sistema que comenzaría a percibirse como inestable con el declive del llamado "estado del bienestar", a partir de los años setenta del siglo $x x$.

Según dicho modelo o ideal de funcionamiento social, sería el mérito individual, propio de la burguesía -esto es, la capacidad de trabajo, la responsabilidad, el talento y el sentido de utilidad, como ya lo vio Weber- el criterio fundamental para el ascenso social, en contraposición a los valores nobiliarios vigentes hasta el 
advenimiento de la contemporaneidad, regidos por el nacimiento o la sangre y el honor (Rey, 1992, p. 19). De ahí que se haya tomado la era burguesa como la meritocrática por excelencia.

En un sentido general, se entiende el mérito como aquella cualidad o capacidad, "acción o conducta», o conjunto de tales, que, en su adecuado ejercicio, gozan de una especial estima social. Que dan "derecho a reconocimiento, alabanza, etc.», según reza el propio diccionario de la RAE (23.a edición, actualizada a 2019). Sería el caso de la «iniciativa» o "capacidad de riesgo» económicos en el caso de la burguesía y empresariado en la era contemporánea; pero, asimismo, de las habilidades militares o guerreras en lo que respecta a la nobleza de casi todos los tiempos (de ella o de sus antepasados). Cualidades, pues, sobresalientes o valiosas para el grupo social dominante por su triple poder: económico, político e ideológico. Pero 'meritocracia' es, además, un sistema de sanción social de los méritos, cualesquiera que sean estos. Por decirlo en términos sencillos, constituiría cualquier sistema que premiara o reconociera en especial a los que la sociedad perciba como mejores, casi siempre los miembros de las clases y grupos dominantes de cada una de ellas, y de los varones a nivel general.

Así, el reconocimiento o exaltación de ciertos méritos (aunque sufran modificaciones en términos históricos) parece haber constituido un medio preferente de legitimación de las posiciones de preeminencia social, y así han tratado de justificarlo a posteriori algunos planteamientos intelectuales. En el caso de la teoría de las elites de Pareto, por ejemplo, la dominación social (que creía inevitable) era "consecuencia de una diferencia esencial entre los "hombres"» (Domínguez, 2013, p. 49). En efecto, la atribución de méritos ha conllevado con asiduidad la concesión de honores, recompensas y privilegios por la realización de funciones y por roles sociales muchas veces ya adquiridos, y que, por tanto, contribuyen a reforzarse por estos medios. El sociólogo Thornstein Veblen advirtió esto en su obra clásica, Teoría de la clase ociosa. En ella, el autor subrayaba la existencia de una continuidad histórica en el hecho de que las clases altas se hubieran reservado desde siempre las tareas «honorables» (1899/1974, pp. 9-10).

Lo dicho concierne por igual a la era contemporánea. Es a partir de este momento cuando se tiende, con preferencia, a premiar, así como a amparar legalmente, el mérito considerado individual; lo cual logrará un éxito definitivo con la ampliación y extensión de los derechos que van siendo reconocidos y consagrados. La cualificación por el mérito se hará pues, en teoría, con independencia de la extracción o condición social, racial, sexual o de cualquier otro tipo de la persona. Sin embargo, el hecho de que las realizaciones, capacidades o virtudes por lo general más apreciadas recaigan en especial sobre los miembros de los grupos de mayor poder (el económico casi siempre incluido), y, en mayor medida, sobre los varones que sobre las mujeres, nos ofrece, nuevamente, un indicio de relevancia acerca de la probable función legitimadora-social y de género- de tales apreciaciones. 


\subsection{El mérito como constante histórica}

Puede resultar ilustrativo traer a colación algunos ejemplos de las justificaciones que de las preeminencias de clase o rango se han ido vertiendo a lo largo del proceso histórico de la llamada civilización occidental. Unas formas de legitimación que, si bien pueden referirse a un grupo o estrato social en su generalidad, concernirán en especial -o incluso de manera exclusiva- al conjunto de los varones del mismo.

Los inicios de la estratificación social suelen situarse en las sociedades tardoneolíticas. En general se acepta que, con estas, y los denominados inicios de la civilización, o sociedades protourbanas, se produjo la ruptura o disolución de la antigua comunidad prehistórica, básicamente igualitaria en lo que se refería al reparto de los recursos en su seno. La complejización productiva -con su correlato, entre otros, de aparición de jefaturas permanentes- debió traer consigo la sustitución progresiva de las pequeñas comunidades autosuficientes de carácter igualitario por grupos jerárquicos o incipientes clases sociales, respecto a las cuales la distribución de los recursos resultaba desigual de forma creciente (Delibes, Fernández-Miranda, 1993, pp. 7-19; Fernández, 2015, pp. 104, 268-9, 340, 344, 347-48, 361, entre otras). Un hecho que se documenta por la aparición del afán de ostentosidad de ciertos individuos y de diferencias suntuarias en los ajuares funerarios. Tal y como lo apreció Veblen, «en el proceso de evolución cultural, la aparición de una clase ociosa coincide con el comienzo de la propiedad» (1899/1979, p. 29).

Aunque parece probable que en las comunidades paleolíticas y neolíticas existiera una división del trabajo entre sexos, esta no tuvo por qué encontrarse muy acentuada (AA. VV., 2006; Cohen, 2011, pp. 145-149, basándose esta última en los estudios de antropólogas como Joan M. Gero y Margaret W. Conkey). No obstante, con la llegada de las profundas mutaciones asociadas al fin del neolítico y la aparición de las sociedades metalúrgicas, es muy posible que el papel de la mujer fuera quedando subordinado al del varón (Godelier, 1981, p. 15; Delibes, Fernández-Miranda, 1993, p. 19). En la agricultura, donde las mujeres habían tenido una importante función, cabe que estas se vieran hasta cierto punto apartadas de esta actividad básica sobre todo a partir de la introducción del arado. Se ha barajado también la hipótesis -enfatizada por Lerner (1990, p. 80 y ss.) y otras autoras feministas, basándose sobre todo en los trabajos de Meillassoux y Lévi-Strauss- de que el intercambio, el comercio matrimonial y la esclavización de mujeres procedentes de grupos conquistados $-\mathrm{y}$ el empleo consiguiente de su capacidad sexual y reproductiva- fueran determinantes en la creación y consolidación del patriarcado. A su vez, el papel central que comenzó a tomar la producción de los metales para la guerra, con un protagonismo indudable en las nacientes civilizaciones, debió apartar asimismo a las mujeres de algunas de las actividades más valoradas a nivel social. 
La preeminencia del varón en las sociedades pre y protoestatales fue exaltada con abundancia. Las habilidades militares en un mundo donde la guerra se convertía en moneda corriente, $y$, con ello, en fuente de enriquecimiento y preeminencia social, resultaron fundamentales; y las hazañas bélicas (e igualmente las agonísticas y de caza) fueron motivo de encumbramiento y glorificación a través del arte y la poesía, como demuestran innumerables ejemplos. Todo ello fue paralelo al ya apuntado proceso de estratificación social, que quedó por completo consolidado con el florecimiento de las primeras civilizaciones históricas y la consiguiente concentración del poder político, militar y religioso.

En el mundo antiguo, la aparición de estratos nobiliarios estuvo ligada a la posesión y ejercicio de habilidades guerreras, y, asimismo, de considerables bienes, con preferencia de los raíces de naturaleza agraria. Así ocurre, por ejemplo, en la Grecia homérica, donde «el estrato de los ricos y poderosos resulta ser esencialmente una nobleza hereditaria, cuyos miembros remontan con orgullo su árbol genealógico hasta los dioses» (Gschnitzer, 2005, p. 61). Este afán por la distinción se acentuará en momentos posteriores, y en época arcaica la nobleza no solo se convierte en un estrato aislado del pueblo llano, esto es, en una aristocracia, sino que abandona "la vía del trabajo; vive sistemáticamente del trabajo ajeno» (Gschnitzer, 2005, p. 91). Aunque observarán un notable desarrollo y transformación, los principios de la educación griega continuarán bebiendo, durante mucho tiempo, de los viejos ideales aristocráticos de "excelencia» o areté (Marrou, 1985, pp. 45-46; Jaeger, 1933/1962, pp. 181-196; Gschnitzer, 2005, pp. 173-182).

En el caso de la Roma preurbana, previa a la decantación de clases sociales, las formas de organización comunitaria -sobre todo la gens- presentan ya netos rasgos patriarcales (con un pater gentis al frente), al parecer ligados a las necesidades de defensa. Con el desarrollo de las primeras formas estatales y sus instituciones políticas (como el senado y las curias -o "reunión de varones» con atribuciones también militares-), no solo acaba de perfilarse una clase dominante, sino que, con ella, se consolida la naturaleza patriarcal de la sociedad (las gentes patriciae, o patriciado romano, procedían de los patres familiae y patres seniores que ocupan y van monopolizando el senado) (Martino, 1985, pp. 34-39; Roldán, 1981, pp. 53-54). Pero tal vez lo más importante, a los efectos de nuestro estudio, es que la legitimación de esa posición de neta preeminencia social (que va unida a la acumulación de poder económico, entre otros) se realiza a través de la atribución de cualidades especiales a esta élite, ligándola a orígenes divinos a través de la figura mítica de Rómulo, fundador de la ciudad de Roma e hijo del dios Marte (Roldán, 1981, p. 37).

La justificación de la posición social del estamento nobiliario durante la Edad Media occidental (principal grupo privilegiado, haciendo excepción de los estratos superiores de la Iglesia, asimismo de extracción nobiliaria en gran medida) continuará remitiendo ante todo a sus capacidades militares, pero irá también más allá. En la Alta Edad Media europea, «si el poder de los grupos privilegiados [...] tiene [...] 
[una] justificación eminentemente militar, sus bases descansan sustancialmente en la riqueza fundiaria que han podido acumular» (Mitre, 1983, p. 95). La tierra, el feudo, se convertirá así en una fuente de prestigio social de primer orden, la cual «era de hecho una recompensa, un regalo o un reconocimiento de los méritos sociales obtenidos por una persona concreta, méritos conseguidos en acciones guerreras o en servicios concretos hechos al poderoso señor» (subrayados nuestros). Es más,

La tierra se "sacraliza» y su disfrute, de hecho, será un verdadero anticipo de la voluntad divina respecto al destino eterno de sus beneficiarios. En otras palabras, la tierra pertenece a los mejores («aristócratas» seglares y eclesiásticos), unos mejores entendidos según la vieja concepción real del mundo helénico. Tierra y predestinación, he aquí algo poco subrayado. En efecto, en el seno de una sociedad integrista tales «mejores» lo eran (debían serlo) en todos los terrenos; Dios estaba con ellos, y por eso mismo debían ser respetados, obedecidos e, incluso, reverenciados. (Jutglar, 1999, p. 27).

Con el tránsito de los siglos de la Edad Moderna, la justificación de la nobleza se va haciendo, por diversas razones, más problemática, a pesar de lo cual continuará teniendo en el nacimiento, la sangre o la «raza» un asiento fundamental. Como con anterioridad, esto implicaba una concepción colectiva de los méritos nobiliarios, ya que se entendía que la idiosincrasia del grupo residía en las virtudes acumuladas por antepasados y contemporáneos a través del linaje; y que a mayor antigüedad de este mayores serían aquellas (Cooper, 1976, pp. 11-16). Unas virtudes que poseían su raíz en el ejercicio de las armas, pero que se encontrarían también presentes en determinados estilos de vida exclusivos (como la largueza en el gasto o la no ocupación en oficios manuales). Unas manifestaciones de prestigio que ejercieron una notable fascinación sobre una pujante burguesía europea. Si bien la extensión de diversos mecanismos de ennoblecimiento -accesibles a los más adinerados-fue poniendo en cuestión ideas tales como la pureza de sangre, estas contaron aún en el XVIII con gran aceptación. Y, en todo caso, aflorarían nuevos recursos de legitimación de la existencia del estamento, como su supuesto papel de contención frente a los desmanes del absolutismo (Rey, 1992, pp. 18-55; Tenenti, 2011, pp. 128-131).

Los principales méritos reconocidos a nivel social han sido aquellos desplegados en la esfera pública. Un escenario el de lo público que, su vez, ha estado dominado por los varones (la palabra latina virtus -virtud- procede de la raíz vir-varón-, y su primera acepción es la de «conjunto de cualidades propias de la condición de hombre»). Este protagonismo casi exclusivo del varón en los círculos decisivos de poder, en la «construcción del mundo»-como fue denominado por Beauvoir-, era lo determinante para la valoración prioritaria de tales 'virtudes'. Salvo contadas excepciones -que demostraban que, con las mismas oportunidades, las mujeres podían llegar a idénticas cotas que los hombres-, estas se veían relegadas a roles pasivos y depen- 
dientes (Beauvoir, 1949/2005, pp. 214-5). Ello determinaba una escasa valoración hacia aquellas tareas y trabajos en los que «las mujeres han sido y son protagonistas indiscutibles», esto es, con los vinculados a "la recreación y mantenimiento de la vida» (Cembranos, Herrero, Pascual, Hernández, Morán et al., 2011, p. 181), poco apreciados con relación a las "gestas» y trabajos "activos», realizados sobre todo por hombres, y en especial por aquellos pertenecientes a las clases dominantes.

$\mathrm{Si}$, en líneas generales, tales rasgos resultaban inherentes a las sociedades europeas previas al advenimiento de la edad contemporánea, a partir de los profundos cambios económicos y sociales generados con la Primera Revolución Industrial, y, sobre todo, con las formidables convulsiones sobrevenidas con la Revolución Francesa, se puso de manifiesto, con el nuevo protagonismo social de los «no privilegiados", que dichas virtudes no eran exclusivas de las que habían sido hasta entonces clases o estratos dominantes. Constituían, por contra, cualidades que podían manifestarse en cada ser humano. No obstante, la nueva sociedad, fundamentada ahora en el dominio de otra clase social, la burguesía, recurrió a nuevos "méritos» que justificaran su preeminencia, como la laboriosidad, la capacidad de iniciativa o la inteligencia práctica, e incluso una moralidad superior (Hobsbawm, 2011a, pp. 192-193; 2011b, pp. 254-5; Kamen, 1984, pp. 120-145). Tales méritos, los clásicos esgrimidos por la burguesía, serán, aun con ciertas variaciones, los que permanezcan vigentes hasta hoy.

\section{LA ERA CONTEMPORÁNEA Y LA SANCIÓN UNIVERSAL DE LA IDEA DE MÉRITO}

A partir de los grandes ciclos de las revoluciones políticas de los siglos XVII al XIX en Europa y América, y con los profundos cambios económicos generados por el desarrollo capitalista, se impone una mayor movilidad social. Lo que significa que, dadas determinadas circunstancias y requisitos, en teoría cualquiera podría acceder a los estratos superiores de la sociedad; esto es, sin que ninguna norma oficialmente sancionada pudiera impedírselo. Así, lo que se entiende como capacidad, iniciativa y mérito personal viene a sustituir, de forma creciente, a la cuna, al linaje, al privilegio hereditario (Kocka, 2000, pp. 30, 39; Fradera, Millán, 2000, p. 16).

Aunque con variaciones importantes según áreas geográficas, así como con limitaciones y resistencias, "puede afirmarse que el resultado más importante de las dos revoluciones [la industrial y la francesa] fue [...] que se abrieran carreras al talento, o por lo menos a la energía, la capacidad de trabajo y la ambición» (Hobsbawm, 2011a, p. 194). Ello tuvo su contrapartida en una redoblada campaña moral dirigida sobre los pobres, campesinos y obreros, a los que se percibía particularmente atrapados por el vicio, como observó Thompson para la revolución industrial inglesa (1963/2012, p. 441 y ss.). 
Lo que se impone, pues, con la era contemporánea, es la competencia casi general para la adquisición de méritos, o lo que es lo mismo, la igualdad formal como derecho a competir desde situaciones de desigualdad, aunque con ello se reprodujeran a su vez estas últimas (Hobsbawm, 2011c, p. 179). Dicho principio de competencia se encontraba mitigado por la institución de la herencia, pues en la nueva sociedad la burguesía crea linajes propios -o se imbrica con los antiguos-, lo que posibilita que sus miembros partan de posiciones muy aventajadas (Hobsbawm, 2011a, p. 189). El cambio sustancial que venía a producirse a partir de entonces, aunque ello se circunscribiera todavía casi por completo a los miembros del sexo masculino, consistía en que, en teoría (y es en esto en lo que radica la igualdad formal), cualquier individuo con suficiente "competencia» (la coincidencia del término no es casual) podía alcanzar posiciones valoradas en el contexto social. Es decir, la idea de mérito o demérito se individualiza mucho más que en las sociedades pasadas. Por otra parte, en una sociedad en la que se imponen las relaciones capitalistas, el Estado se erige en árbitro de tales luchas, postulándose en garante de la «libre competencia».

\subsection{Las consecuencias para las mujeres}

Las cualidades que posibilitaban la consecución de los más valorados méritos a nivel social eran atribuidas en exclusiva a la naturaleza masculina, por lo que la competencia se circunscribía a los varones, en especial a los de cierto nivel económico. De esta forma, las posibilidades de las mujeres para el ascenso social quedaban restringidas casi por completo al matrimonio o la herencia. Estas quedaban excluidas "de la esfera pública y de la ciudadanía» y, por tanto, también de los mecanismos propios de la sociedad meritocrática burguesa, tomándose esta situación «como perpetua, no modificable y no contradictoria, por derivar de la naturaleza y de las diferencias "esenciales" y "naturales" entre mujeres y hombres, que hacían de las primeras seres no independientes, no autónomos, y casi no "racionales" » (Aguado, 2005, p. 14).

Pero gracias a esta enunciación de un principio general de igualdad formal (aunque no fuera en realidad ni neutro ni de alcance universal), comienzan a abrirse en las sociedades occidentales contemporáneas, con lentitud y precedidas de numerosas luchas, mayores posibilidades para la promoción de las mujeres, amén de otros grupos excluidos. Sirvieron al menos de cauce para nuevas pugnas por la liberación, que van forzando algunos cambios (Mies, 1986/2019, p. 62). Era lo que en ocasiones se ha denominado apertura de la "caja de Pandora», en tanto que «la teórica universalidad de los principios ilustrados comienza a ser planteada por parte de algunas o algunos como algo que puede llegar a ser radicalmente real» (Aguado, 2003, p. 65; véase también Nielfa, 1995, pp. 104 y ss.). Así, las primeras grandes vindicaciones de derechos de la mujer, como la de Olimpia de Gouges 
durante la Revolución Francesa, la de Mary Wollstonecraft por las mismas fechas, o la Declaración de Seneca Falls en 1848, a pesar de su protesta por la exclusión de las mujeres respecto a los derechos universales que había proclamado la razón ilustrada, tendrán inevitablemente entre sus fundamentos teóricos los propios principios ilustrados y revolucionarios (Aguado, 2005, p. 15; Ballarín, Birriel, Martínez, Ortiz, 2000, p. 40; Capel, 2014, pp. 71-72).

Aunque existían precedentes de lucha contra la idea asentada de inferioridad y subordinación de la mujer, es, pues, con la era contemporánea cuando van surgiendo nuevas condiciones que favorecen la transformación de dichos modelos culturales a mayor escala (Nash, 2004, p. 54; Nielfa, 1999, pp. 63-65). Impulsada a lo largo del tiempo por diferentes circunstancias -entre otras, la sociedad tecnológica, el papel de las mujeres en los nuevos contextos bélicos o la competencia con las sociedades socialistas-, la idea de la igualdad formal y, de forma más reciente, la llamada igualdad de oportunidades (que viene a ser una reformulación de la primera), ha constituido un eje fundamental en dicho proceso.

\subsection{La persistencia del elitismo}

Que las sociedades occidentales contemporáneas se forjen sobre fundamentos meritocráticos muy acusados no resulta incompatible con la naturaleza democrática que, de manera paulatina, van tomando sus sistemas políticos e institucionales, sobre todo a partir del siglo Xx. La clave se encontraría en el denominado carácter "abierto» de dichas sociedades al ascenso social, más fluido conforme se avance en la consecución de derechos.

No se pretende entrar aquí en los presupuestos antropológicos o filosóficos de dicha concepción meritocrática; pero sí que cabe resaltar el neto carácter social que ha tomado en la actualidad esta noción individualista (Beck, Beck-Gernsheim, 2003, pp. 27-30). Este origina, entre otras consecuencias, que los considerados "triunfadores» en el sistema de competencia universal basculen por lo común hacia autovaloraciones de superioridad (sea como individuos o conjunto). Esto es, que se desarrolle un darwinismo social o un elitismo de nuevo cuño perceptible en actitudes variables de indiferencia o desprecio hacia grupos e individuos que se encuentren al margen de este colectivo escogido, incluso aunque este último pueda ser bastante amplio (Currid-Halkett, 2017; Lasch, 1996, pp. 33-49; Reeves, 2017, p. 32; Todd, 2010, pp. 72-73). Los citados Beck y Beck-Gernsheim sostenían la tesis de que «la desigualdad social está en aumento precisamente a causa de la difusión de la individualización» (2003, p. 33). La meritocracia, de hecho, parece ser un fuerte disolvente del sentimiento comunitario fraternal (Bauman, 2003, 71-73).

El hecho de que, por lo común, se encuentre fuera de todo cuestionamiento la supuesta excelencia de las élites, supondría otra manifestación relativa a una concepción social meritocrática individualista. La extendida «creencia en que [...] el 
elitismo es eficiente (porque el bien de muchos sólo puede ampliarse promoviendo capacidades que relativamente pocos, por definición, poseen)" sería solo una de las "realidades incuestionables» o "ideas de injusticia» "que raramente se ponen en duda, en realidad falsas creencias que son responsables de la pesadilla de la desigualdad social y su crecimiento aparentemente imparable» (Bauman, 2014, pp. $35,43)$.

Estas ideas formarían parte de un "argumento pragmático» de la desigualdad, según el cual, esta, sostenida en ciertos niveles, sería beneficiosa para todos. Así, por ejemplo, Rawls considerará justicia social la mejora, en términos absolutos, de la posición social de los grupos sociales menos aventajados (es el que llama «principio de diferencia»), aunque ello implique el ahondamiento en las distancias relativas entre los grupos sociales (Comín, 2011, pp. 86-91). De esta forma, el aumento de la riqueza no constituiría un fin compartido salvo desde el entendimiento de que aquel sirve de base para una competencia social con mayores oportunidades para cada grupo social interviniente, $y$, en última instancia, para cada individuo en función de sus méritos (identificados casi unívocamente con una forma muy determinada de «emprendimiento»). El propio Rawls considera que los fines humanos, aunque no posean fundamentos de carácter egoísta, resultan en última instancia inconciliables, y que solo en una sociedad de "santos» sería posible que todos trabajaran desinteresadamente por un verdadero fin común (Rawls, 1995, p. 129).

De esta forma, se justificaría el ingreso de cuantiosas rentas, o la conformación de crecidos patrimonios, aunque varíen los criterios respecto a los niveles aceptables de los mismos. Según Jones (2015, p. 15), lo que unificaría a un variopinto establishment sería "una mentalidad común, que mantiene que quienes están en lo más alto se merecen su poder y sus fortunas cada vez mayores». Lo que sí resulta claro es que dicho estatus superior debe encontrarse demarcado con claridad (en calidad de vida, ostentación u otras circunstancias) para poder ejercer un notable contraste con la calidad y nivel de vida de los grupos que quedarían por debajo de aquél.

Existen muchos ejemplos de la persistencia del elitismo en las sociedades occidentales contemporáneas, algunos ya referenciados. Es más, con el ocaso reciente de las ideologías y los sistemas socialistas, semejante elitismo parece haber florecido con nuevos bríos (Jones, 2015, p. 25; Nagle, 2017, pp. 1, 3; Spire, Hugrée, Penissat, 2017, p. 24). En los Estados Unidos se constata, al menos desde los años noventa, un debilitamiento de las políticas sociales por la tendencia a la culpabilización al pobre de su situación (Arrow, Bowles, Durlauf, 2000, p. XI). Este repunte de la mentalidad meritocrática ha ocurrido incluso al amparo de políticas consideradas «progresistas» o de redistribución social que han dado lugar al engrosamiento de nuevas clases medias que con frecuencia han resultado reacias al mantenimiento de los gastos y las políticas sociales que les ayudaron a prosperar. Este efecto ha resultado visible, por ejemplo, en las sociedades latinoamericanas que contemplaron 
el acceso al poder de los llamados gobiernos de la «nueva izquierda» a partir de finales de la década de los noventa, como Brasil o Bolivia (Lambert, 2018, p. 8; Mariette, 2019, pp. 10-12). En ellas, poblaciones antes modestas o depauperadas que alcanzaron posiciones más elevadas en la escala social (que continuó, por tanto, desigual), generaron actitudes elitistas y formas de vida consumistas. En estos colectivos pudo apreciarse también el debilitamiento de sus anteriores referentes ideológico-políticos y sus formas de lucha comunitarias (Mariette, 2019, pp. 10-12).

En paralelo tenemos la ola neoconservadora y de rasgos autoritarios que, en especial a raíz de las secuelas generadas por la gran crisis de deuda de 2008, ha ido encontrado acogida entre las poblaciones, electorados y gobiernos de muchos países y puntos del globo. Estos movimientos, aunque con ciertos grados de heterogeneidad, se caracterizan, entre otros atributos, por un marcado elitismo, sobre el cual se fundamenta una acendrada defensa del sexismo, cuando no una mal disimulada misoginia. Algo muy visible, por ejemplo, entre la "Derecha Alternativa» de Estados Unidos (Almansa Pérez, 2019). Asimismo, en Brasil, el gobierno del ultraconservador Bolsonaro -un político que se distinguió desde un comienzo por "sus salidas sexistas, homófobas, favorables a la tortura» (Lambert, 2018, p. 8)-, ha apelado a una especie de restauración de la meritocracia, que consideraba amenazada por las políticas sociales del anterior partido gobernante (Muvuca Popular, 2019; Vigna, 2017, pp. 1, 7).

Cabe inscribir lo anterior en una reacción, al parecer creciente, hacia la mujer en general, así como hacia el feminismo en particular (como puede observarse, a modo de ejemplo, en Caballero, 2016; o en Women, s. f.). Para Segato (2016, pp. 16-17), nos encontramos en un contexto de profunda crisis que favorece las posturas y opciones reactivas, tanto de redoblada defensa del capitalismo como de las estructuras y dinámicas patriarcales. A ello respondería una nueva oleada en pro del reforzamiento de la concepción naturalizada de las desigualdades humanas (Cobo, 2011, p. 70).

Esta agudización de los sentimientos elitistas, sobre todo entre los grupos sociales más privilegiados, ha generado algunas alarmas. Desde hace tiempo se alzan voces que alertan del peligro que corren los sistemas democráticos mismos (Crouch, 2004, pp. 10-15, 39-40; Lasch, 1996; Todd, 2010, p. 193 y ss.), entre otras cosas, porque determinados sectores instalados en fuertes planteamientos meritocráticos vienen cuestionándolos. Tampoco faltan estudiosos que relacionan el éxito reciente de las opciones ultraconservadoras -capaces de combinar con eficacia populismo con elitismo- con su confrontación con opciones elitistas tildadas de «progresistas». Así ha ocurrido, por ejemplo, en Estados Unidos, donde el amplio respaldo popular proporcionado a la candidatura conservadora que accede al gobierno a partir de 2017 se ha interpretado como una reacción al fuerte exclusivismo desplegado por las clases medias-altas cosmopolitas de las franjas costeras, que no han ocultado durante mucho tiempo su desprecio hacia las que perciben como 
masas ignorantes y paletas (Hochschild, 2016, pp. 221-230; Nagle, 2017, p. 3; Lasch, 1996, pp. 15, 33-38).

Se ha constatado a menudo que los sistemas meritocráticos o elitistas pueden implicar ineficiencia económica. A pesar de los indudables logros respecto a los niveles de producción material y progreso tecnológico del capitalismo, el mencionado Veblen evidenciaba cómo, en los Estados Unidos de finales del siglo XIX, sus clases altas debían sujetarse a la ostentosidad y el derroche permanentes si pretendían mantener su estatus. Una situación que él atribuía a un requerimiento de autovaloración casi compulsivo, producto de una subjetividad débil, basado en la comparación permanente con el grupo de iguales o inmediatamente superiores. Varias décadas más tarde, el economista J. K. Galbraith, lamentaba, en una edición tardía de su obra más famosa, La sociedad opulenta, cómo el crecimiento insospechado de la prosperidad material de ciertas clases, gracias al desarrollo industrial norteamericano, había incrementado las tensiones sociales y generado ingentes necesidades económicas (1958/1985, p. 18). En los años setenta, otro economista notorio, E. F. Schumacher, ponía el dedo en la llaga respecto a la irracionalidad ecológica y humana de un sistema (en realidad, anti económico) basado en la gran acumulación y el aumento permanente del consumo (1980, pp. 53-54). Y por finalizar esta breve enumeración, en fechas más recientes, el premio nobel Joseph Stiglitz resaltaba la ineficiencia inherente a la escandalosa acumulación económica producida en los Estados Unidos desde hace algunas décadas (2015, pp. 109, 118).

Este último, como otros autores (Brooks, Mcquaig, 2014), achacaban esta situación de ineficiencia a una perversión, o falta de cumplimiento real, de los principios de una sociedad meritocrática. Es decir, el problema radicaría, según ellos, en que no están siendo los verdaderamente talentosos los más beneficiados de la acumulación de bienes económicos. Una apreciación que sitúa la mirada crítica en el meollo de los ultrarricos, pero que presta poca atención a las clases medias-altas, que suponen un porcentaje bastante mayor de la población. Según algunos estudiosos, estas últimas se caracterizarían asimismo por su elitismo (si bien no siempre ostentoso o evidente), aunque desarrollen hábitos de consumo y de vida diferentes a los de las clases altas anteriores a las dos guerras mundiales. Acumularían, además, un volumen de rentas y recursos muy considerable y, en ocasiones, se percibirían a sí mismas como "progresistas» (Currid-Halkett, 2017; Halimi, 2017, p. 32; Raim, 2018, pp. 22-23; Reeves, 2017, p. 32). Como afirma el citado Halimi, frente al $1 \%$ de los considerados muy ricos,

el $99 \%$ reúne indistintamente a los condenados de la tierra y a una clase media superior, bastante densa, de médicos, expertos universitarios, periodistas, militares, altos ejecutivos, publicistas, altos funcionarios sin los cuales la dominación del $1 \%$ no resistiría más de 48 horas. (Halimi, 2017, p. 32). 
Tal y como lo expresaba el historiador y sociólogo Christopher Lasch para la clase media-alta de profesionales de Estados Unidos en los años 90,

aunque las ventajas hereditarias desempeñan un importante papel en el logro de un nivel profesional o directivo, la nueva clase tiene que mantener la ficción de que su poder se basa exclusivamente en su inteligencia. [...] Se concibe a sí misma como una élite que sólo debe sus privilegios y posición actuales a sus propios esfuerzos. (Lasch, 1996, p. 42).

Un alto nivel de vida que no solo habría desplazado, hasta cierto punto, a clases medias y bajas de sus propios países, sino que se encuentra, dados los mecanismos imperialistas y de mercado, en relación y fuerte contraste con los niveles de renta de las clases depauperadas de extensas regiones del globo. Como afirmaba Piketty, "el grupo social constituido por el milésimo superior (4,5 millones de personas, poseedoras en promedio de unos 10 millones de euros) es dueño de alrededor de $20 \%$ de la riqueza mundial, suma mucho más sustancial que el 1,5\% de los multimillonarios de Forbes» (Piketty, 2014, p. 483).

\section{LA SITUACIÓN ACTUAL DE LAS MUJERES}

Si lanzamos una mirada general a la evolución reciente de la situación de las mujeres, resultan indudables los avances logrados en la conquista de derechos en igualdad con los varones, en especial en el último siglo. Así, en un informe de 2018 de la OIT sobre tendencias del empleo femenino, se resaltaba que

Los últimos veinte años han sido positivos para la situación de la mujer en el mundo del trabajo y la igualdad de género en la sociedad. La cantidad actual de mujeres instruidas y que participan en el mercado laboral no tiene precedentes, y hay más conciencia de la importancia crucial de la igualdad de género en las iniciativas para reducir la pobreza e impulsar del desarrollo económico. (OIT, 2018, p. 5).

Sin embargo, se concluía de inmediato que "pese al progreso logrado hasta ahora y al empeño en seguir avanzando, las perspectivas de la mujer en el mundo del trabajo distan mucho de ser iguales a las de los hombres» (OIT, 2018, p. 5). Y aunque, en conjunto, en los países desarrollados las tasas de ocupación masculina y femenina se acercarían a la paridad, la persistencia, también en estos últimos, de una considerable brecha salarial, continuaría poniendo de manifiesto «la segregación ocupacional y la polarización de los trabajadores por género de las industrias y de los sectores económicos» (OIT, 2019, p. VI). Esto se produce aun con la existencia de niveles educativos similares, o incluso mejores, en el caso de las mujeres. Otro 
de los factores que, según la misma fuente, influyen en esta situación, se encuentra en la gran cantidad de trabajo llamado invisible, no remunerado o de cuidado, que realizan las mujeres en todo el mundo.

El desarrollo económico y formativo anejo a la evolución de las sociedades contemporáneas occidentales, y asimismo durante el periodo más reciente de la llamada globalización, no ha supuesto, pues, una superación de los estereotipos de género, la discriminación y la violencia (Amorós, 2008, pp. 53-54, 213 y ss.; Vara, 2006, pp. 75-78; Villota, 2004, pp. 131-142). Las situaciones de desigualdad entre sexos, que se manifiestan en diferentes y múltiples ámbitos, persisten, arraigadas con fuerza, como es visible en países como Estados Unidos (Beaugé, 2016, pp. 6-7), Francia (Andrzejewski, 2017, pp. 16-17) o España (Bericat, Sánchez, 2008). Por no hablar de sociedades como la mejicana, entre otras latinoamericanas, donde los altísimos índices de asesinatos y violencia contra las mujeres han llevado incluso a proponer el término de "femigenocidio» (Segato, 2016, p. 22).

La situación de desigualdad básica y estructural en las sociedades contemporáneas incluye, por tanto, a las mujeres como una de sus víctimas fundamentales. No solo asistimos a un incremento notable de las disparidades económicas mundiales, así como en el interior de los países occidentales, desde los años setenta (Piketty, 2014, pp. 383-385, 476-483; 2015, pp. 32-38; también, para algunos datos y referencias, Bauman, 2014, capítulo 1), sino que, además, las mujeres vienen a constituir, con el desarrollo reciente de la globalización capitalista, y junto con el conjunto de la población migrante, una especie de nuevo proletariado mundial (Cobo, 2016, pp. 149, 151). Un tercer informe de la OIT, referido en esta ocasión al año 2016, arrojaba, entre otras, la estremecedora constatación de que «las mujeres y niñas están desproporcionadamente afectadas por la esclavitud moderna; alcanzan una cifra de 28,7 millones, lo que equivale al 71 por ciento del total general de las víctimas» (OIT, 2017, p. 10).

Ahora bien, el mantenimiento de la discriminación femenina y la desigualdad resulta compatible con el hecho de que un restringido número de mujeres haya accedido a puestos y situaciones de preeminencia social. Ello a pesar de que las mujeres, como colectivo, hayan continuado viéndose afectadas por el fenómeno denominado «techo de cristal» (Wirth, 2002, pp. 53 y ss.).

Este acceso creciente de mujeres a puestos de poder y responsabilidad, aunque lento y casi nunca equiparable al que acaparan los varones, suele encontrarse en estrecha correspondencia con su propia situación de clase. En otras palabras, serán mujeres que cuenten con una posición previa de privilegio en la escala social las que, preferentemente, alcancen nuevas posiciones de poder e influencia. De esta manera, aunque una mayor participación política de las mujeres, así como su equiparación con el varón en derechos formales, constituyen exigencias del todo legítimas y necesarias, tales logros no pueden ser siempre considerados síntomas de un fenómeno general de su liberación. Se trataría de una situación de «universalismo 
ficticio» sobre la que advirtió ya Bourdieu a finales de los noventa (2000, p. 141). Este hecho ha sido percibido, desde hace tiempo, por buena parte del pensamiento feminista, como fue el caso de los llamados radical y socialista, amén de otras autoras posteriores (Armanian, 2016a, párr. 5; Fraser, 2015, pp. 14-15; Phillips, 1996, p. 81). Así, por ejemplo, la historiadora feminista Joan Kelly expresaba esta idea en los años ochenta cuando afirmaba que «la opresión sexual no será ella misma superada sin la liberación de todas las formas de dominación y jerarquía» (Kelly, 1984, p. 56). Es más:

Los objetivos no son ni participar como iguales en el mundo del hombre, ni devolver a la mujer su dignidad y valor. Concepciones como éstas son sustituidas en la voluntad actual de extirpar la jerarquía de género y sexo juntas, y con ellas todas las formas de dominación. [...] Una política feminista que aspira abolir todas las formas de jerarquía como a reestructurar las relaciones personales como relaciones entre iguales tiene que alcanzar y transformar la organización social del trabajo, la propiedad y el poder. (Kelly, p. 60, trad. propia).

En un sentido similar, desde una perspectiva centrada en el llamado Tercer Mundo, la socióloga Maria Mies cuestionaba hace ya años la afirmación de que «el desarrollo para dar alcance a los más adelantados libera a las mujeres», y señalaba cómo las grandes promesas de libertad, igualdad y autodeterminación individual de la Revolución Francesa están falseadas desde el momento en que su realización se restringe a los poseedores de capital. Además, afirmaba que «en una estructura de estas características no existe una base material para una solidaridad internacional entre las mujeres» (Mies, 1997, pp. 101-106). Asimismo, resaltaba cómo la división del trabajo existente a nivel mundial propiciaba un entramado y jerarquía de explotaciones de las que también se beneficiaban hasta cierto punto «las pequeñas y grandes mujeres blancas» del capitalismo rico, así como «las grandes mujeres negras de las colonias», mientras que en lo más bajo de la pirámide se encontrarían las mujeres, sobre todo las de color, más desposeídas del capitalismo pobre (Mies, 1986/2019, pp. 266-267).

Un ejemplo de este fenómeno lo tenemos en Estados Unidos, donde el ejercicio de la política requiere, desde hace tiempo, de grandes fortunas que lo respalden. Una propensión que se ha agravado al menos desde la última década (Confessore, Cohen, Yourish, 2015; Mcchesney, Nichols, 2013, pp. 2-3, 11-34). En un Congreso como el norteamericano, donde existe una muy amplia proporción de millonarios y acaudalados (Choma, 2014), un nutrido sector de la representación femenina (aunque inferior a la de los hombres) sigue esta tendencia, tal y como revelan algunos informes independientes (Hawkings, 2018, párr. 14).

Circunstancias similares se muestran en otros países. En América Latina, aunque se viene produciendo desde hace años un mayor acceso de las mujeres a la 
política, muchas de ellas continuarían aplicando medidas conservadoras, incluso en lo social, en un contexto patriarcal muy acusado (Oualalou, 2012, pp. 18-19). Además, una significativa proporción de tales mujeres provendría de las oligarquías dominantes. Algo que sucedería en países como Brasil (Kaipper, 2014) o Colombia (Bernal, 2014, pp. 295-296). Por poner otro ejemplo, en Chile, país marcado por importantes desigualdades sociales y de género, un fuerte peso del conservadurismo social y la incidencia de duras políticas neoliberales, «en las altas esferas del Estado, algunas mujeres han logrado abrirse camino (siempre y cuando no cuestionen el statu quo)» (Gaudichaud, 2019, p. 16).

Esta tendencia general de acceso creciente, pero selectivo, de mujeres a puestos de cierto poder y responsabilidad, parece haber continuado desde el advenimiento de la era neoliberal, e incluso haberse acentuado, sobre todo a partir de la última década, tal y como han denunciado, con dureza, algunas pensadoras feministas. Así, la antropóloga argentina Segato se preguntaba por qué

los think-tanks del Norte geopolítico parecen haber concluido que la fase actual demanda mudar el rumbo de la década anterior, en la que endosaron un multiculturalismo destinado a originar élites minoritarias - de negros, de mujeres, de hispánicos, de LGBTs, etc.- sin modificar los procesos de generación de riqueza, ni los patrones de acumulación/concentración y, por consiguiente, sin alterar el creciente abismo entre pobres y ricos en el mundo. (Segato, 2016, p. 16).

En un sentido similar se pronunciaba la filósofa norteamericana Fraser a raíz de la victoria electoral de Donald Trump en su país. La autora achacaba buena parte de la responsabilidad de este hecho al dominio, durante años, de lo que denominaba "neoliberalismo "progresista"», que vendría a consistir en "una alianza de las corrientes principales de los nuevos movimientos sociales (feminismo, antirracismo, multiculturalismo y derechos de los LGBTQ), por un lado, y, por el otro, sectores de negocios de gama alta "simbólica" y sectores de servicios (Wall Street, Silicon Valley y Hollywood)» (Fraser, 2017, párr. 3). De esta forma:

Identificando "progreso» con meritocracia en vez de igualdad, con esos términos se equiparaba la «emancipación» con el ascenso de una pequeña elite de mujeres «talentosas», minorías y gays en la jerarquía empresarial del quien-gana-se-queda-contodo, en vez de con la abolición de esta última. Esa comprensión liberal-individualista del «progreso» vino gradualmente a reemplazar a la comprensión anticapitalista -más abarcadora, antijerárquica, igualitaria y sensible a la clase social- de la emancipación que había florecido en los años 60 y 70. (Fraser, 2017, párr. 5).

Tales procesos se han producido, además, en un contexto más amplio en el cual el ámbito de autonomía de lo político cede frente al poder creciente de la 
corporación y de los grupos de presión empresariales al menos desde finales del siglo XIX, si bien dicha tendencia se incrementa de forma notable desde los años setenta (Musso, 2019, p. 3; George, 2015, pp. 25-29). Dicho en otras palabras, las instituciones políticas, como, asimismo, otros tipos de entramados institucionales, se encontrarían en una posición según la cual su función preponderante sería la de garantizar la satisfacción de los principales intereses empresariales, esto es, la continuidad en la reproducción ampliada del capital (Robinson, 2014, pp. 24-27). Una lógica que, sin embargo, como ya puso de manifiesto el economista Polanyi en los años cincuenta -y había denunciado Marx mucho antes-, se caracteriza, en esencia, por la mercantilización y reducción a puro objeto del trabajo humano y de la propia naturaleza. Esto era la consecuencia, según el primero, de que el mercado se hubiera transformado en el gran regulador de la vida social; un mercado que era considerado capaz, por sí mismo, de autorregularse. Con ello, este último y, en su conjunto, la propia economía capitalizada, trataban de suplantar a la vida misma, privándola de su sentido propio, y, así desustancializada, emplearla para sus fines (Polanyi, 1957/2003, pp. 90, 217-218; véase también Gorz, 1997, p. 37). A estas mismas premisas respondía el razonamiento del influyente economista liberal Mises cuando afirmaba que «un solo razonamiento válido hay contra la esclavitud [...], a saber, que el trabajo del hombre libre es incomparablemente más productivo que el del esclavo» (1927/1994, p. 39).

Instituciones de control, influencia o regulación económicas, e instituciones políticas en general, resultan, pues, bastiones clave para el mantenimiento y optimización de las lógicas permanentes de acumulación del capital (a través del mercado o por otros medios). Lo que no significa que, a través de tales instituciones, no se introduzcan también, en mayor o menor proporción, y según coyunturas, medidas de cierta «redistribución» económica que, no obstante, dejan incólumes los mecanismos fundamentales de salvaguarda y acumulación de la propiedad y acceso a los recursos esenciales, incluyendo la naturaleza y el trabajo humano. Ello significaría que las mismas instituciones contribuyen -aunque sea de forma modulada $y$, en ciertos contextos, con compensaciones- al mantenimiento de las desigualdades sociales y sus criterios meritocráticos anejos, los cuales, como se ha visto, incluyen a menudo los de género.

\section{5. el trabajo de las MUjeres, POLO OPUESTO de la valoración MERITOCRÁTICA}

Afirmaba hace unos años el filósofo francés de inspiración marxista Lucien Sève que la «alarmante deriva» de nuestra civilización "que salta primero a la vista, es la mercantilización generalizada de lo humano" (Sève, 2001, p. 16, subrayado en el original). Aunque tal mercantilización no constituiría un fenómeno nuevo, según 
el propio Marx «en ningún otro período anterior [a la extensión del maquinismo] habían llegado las fuerzas productivas a revestir esta forma indiferente para el intercambio de los individuos como individuos, porque su intercambio era todavía limitado» (Marx, La ideología alemana, citado por Gorz, 1997, p. 39).

Si resulta cierto que nos hallamos inmersos en una crisis de paradigma -y así viene hipotetizándose desde hace tiempo (Beck, Beck-Gernsheim, 2003, p. 64; Fernández Buey, 2009)-, entonces parece primordial cuestionar tal modelo de mercantilización/instrumentalización. Este habría tomado hegemonía con la mundialización capitalista, en especial a partir del siglo XIX. Así, Naredo señala que, en el siglo XVIII, con la fisiocracia, surge una concepción de la economía ligada al crecimiento económico, y, con él, a lo venal, frente a la «economía natural» anterior (2006, pp. 4-6). Si entendemos por instrumentalización el hecho de que se tome a la naturaleza y los propios seres humanos no como fines en sí mismos, sino en tanto que medios para otros fines externos a ellos, en efecto, dicha concepción, hecha ya señera, se encontraría en la base de los mecanismos actuales de depredación masiva de la naturaleza y de desvalorización y expropiación (con todo lo que ello implica) de millones de seres humanos. Una realidad ligada, a su vez, de forma inextricable, a sistemas de jerarquización o estratificación social (mundiales y nacionales) que asignan diferentes capacidades de detracción de recursos y desiguales calidades de vida en función de supuestos méritos individuales, pero también distribuidos socialmente (incluyendo, una vez más, los basados en el género).

Ya se ha señalado que determinados puestos de poder, inscritos en tales lógicas de acumulación del capital y reproducción de las desigualdades (sea en su esfera económica, como en la política, social o ideológico-cultural) contribuyen a la instrumentalización de la vida. Con ello se oponen, en última instancia, a la afirmación plena de esta, poniéndola, incluso, en grave peligro desde muchos puntos de vista (Herrero, 2010, pp. 17-31; Hinkelammert, Duchrow, 2004; Naredo, 2006, pp. 36-38; Pérez-Orozco, 2015, pp. 83-86). A este respecto, afirma Federici (2010, p. 32), que «el capitalismo, en tanto sistema económico-social, está necesariamente vinculado al racismo y al sexismo» ( $y$, añadiríamos, al darwinismo social), mientras que, según Robinson (2014), «el capitalismo, y por lo tanto la clase capitalista [...] siempre ha dependido -y aún lo hace en la fase trasnacional del sistema- del trabajo no remunerado de las mujeres y de la creación de reservas de trabajo étnico superexplotado» (p. 59).

¿Qué papel pudieran tener las mujeres, en tanto que colectivo relativamente diferenciado, en la posible superación del actual modelo competitivo-meritocrático? ¿Pudieran ellas conformar, de alguna manera, un eje vertebrador, o factor aglutinador, de nuevos planteamientos de igualdad, más profundos en tanto que fueran más allá de la mera declaración abstracta de derechos? Y también, ¿ pudieran servir la propia trayectoria histórica de las mujeres y su situación mayoritaria en el mundo (con rasgos comunes en aspectos esenciales, aun con diferencias), para promover 
experiencias y modelos de humanización radical, en tanto que superadores del clasismo y el sexismo, y, en general, de todo mecanismo o sistema de desvalorización humana?

Cabe decir que la situación mayoritaria de las mujeres, al margen de los mecanismos de reproducción del capital, el poder clasista y sexista y el estatus, las sitúa en una situación singular. Aun con excepciones, ya hemos señalado cómo las mujeres continúan encontrándose marginadas, en proporciones considerables, de muchos puestos relevantes de poder y decisión en todo el mundo. Por poner solo un ejemplo, los porcentajes de participación política de las mujeres son aún reducidos en muchos países, incluyendo zonas de Europa y el continente americano, aunque la tendencia es al alza (ONU Mujeres, 2019). Esta situación de injusticia las colocaría, sin embargo, como tal colectivo marginado, en condiciones de ofrecer posibles alternativas al modelo competitivo-meritocrático imperante. Todo ello, además, teniendo en cuenta que las expectativas de lograr

la liberación de la mujer presionando al Estado y recibiendo de esta manera mayores recursos sociales, o exigiendo igualdad de oportunidades para la mujer en el mercado laboral, especialmente dentro de las posiciones de mayor relevancia de este mercado, o mediante el aumento de la participación de las mujeres en la política y en otros cuerpos de toma de decisiones, han visto aplastadas sus expectativas. (Mies, 1986/2019, p. 60).

Pero, además, como se ha visto, muchas mujeres han venido realizando, y continúan haciéndolo, trabajos considerados «invisibles», esto es, mal retribuidos o sin retribuir, llevados a cabo en ocupaciones de escasa valoración social; se dedican a contribuciones gratuitas o semi gratuitas a su familia, colectividad, patronos o empresa, o a los denominados "cuidados», esto es, labores imprescindibles para la reproducción y el mantenimiento de la vida. El volumen y la trascendencia de tales tareas, junto a su escaso reconocimiento, han sido puestos de manifiesto por una literatura feminista muy abundante, en especial en las últimas décadas (Amoroso, Bosch, Carrasco, Fernández, Moreno, 2003; Carrasco, 2006a, 2006b, 2013; Carrasco, Borderías, Torns, 2011; Durán, 2008; Pascual, 2010; Pérez Orozco, 2006, 2014, 2015; o Piccio, 2001, entre otras muchas). Una dedicación que se encuentra en el polo opuesto de la valoración social meritocrática, protagonizada sobre todo por hombres.

Excluidas durante mucho tiempo de la esfera pública, las mujeres se vieron recluidas en el ámbito privado o aisladas en trabajos muy feminizados, donde sus funciones y quehaceres nunca pudieron entrar en competencia con las de los varones. Como supo ver Simone de Beauvoir (1949/2005), las actividades ligadas de manera más estrecha a la "transformación del mundo", aunque fueran de carácter manual, eran de atribución preferente a los varones; y en tanto que ligadas a esa 
modificación activa, que dotadas de ese carácter «creativo» (puesto que se dirigían a un "exterior»), se consideraban "reales», revestidas del aura de lo "verdadero». Las propias de las mujeres, en cambio, centradas más en la esfera de lo doméstico y lo reproductivo, carecerían de tal potencial transformador: se concebían como privadas de verdadera trascendencia. En consecuencia, donde se podían medir los méritos era, en exclusiva, en el mundo "real», donde se entablaban la lucha y la competencia. Las virtudes "femeninas», en cambio, se circunscribían a su círculo, el cual, además, carecía de auténtica sustancia, puesto que solo cobraba completo sentido con relación al masculino.

Ahora bien, ha sido precisamente esa situación, aun con todas las consecuencias penosas que ha arrojado sobre las mujeres, lo que ha rubricado parte de sus actividades no solo con el sello de la necesidad, sino también del "des-interés». Esto es, se trataría de labores no-interesadas en la medida en que eran no lucrativas, no perseguían una recompensa ampliada de continuo, el reconocimiento de un mérito, el logro de un estatus o una posición de poder: podían realizarse, una vez asegurada la reproducción de las condiciones de existencia (o al mismo tiempo que estas se aseguraban), por sí mismas. Ello concerniría de forma directa (aunque no privativa) a los llamados trabajos de cuidados (que se relacionan por lo común con la crianza de los hijos y la atención a otras personas dependientes o no, el mantenimiento del hogar $u$ otros espacios comunitarios, y las actividades no asalariadas del sector primario). Todo lo anterior no obvia que ni la posición (social, económica, familiar) de la mayoría de las mujeres, ni las funciones que debían asumir, no estuvieran acuñadas asimismo con el molde de la fatalidad, pues respondían en buena medida ellas mismas -y siguen haciéndolo- a relaciones de subordinación o explotación. Sin embargo, ello no impide situarlas al margen de los mecanismos de competencia e instrumentalización.

Esta capacidad de afirmación de la propia actividad y, sobre todo, de la vida por sí misma, constituye el carácter distintivo de toda relación que no persigue la cosificación, la comparación desvalorizadora o la explotación de otros seres; se conforma, pues, como lo opuesto al patrón de instrumentalización. Este pretende, ante todo, sacar provecho, emplear algo con fines externos a él mismo (como ocurre con el instrumento inerte). En cambio, en las formas de vida y trabajo más posibilitadoras de la afirmación vital en su totalidad, lo instrumental queda subordinado a esto último; no se impone como el fin primordial, sino como lo que es: un medio. Es por esto, en un sentido profundo (y no solo biológico), que se han podido asociar las actividades de muchas mujeres a la afirmación de la vida en tanto que opuestas a las lógicas de acumulación, despojo, explotación y desvalorización. Y por esto asimismo se ha sostenido que, a pesar de todas las limitaciones impuestas por los condicionantes históricos, la labor de las mujeres ha constituido un factor de humanización de primer orden (Carrasco, 2013, pp. 41-42, 48; Flecha, 2004, pp. $25,31)$. Un papel que continúa hoy reivindicándose con singular urgencia a través 
de enfoques como el de la economía feminista o el ecofeminismo (Mora, Escribano, 2015; Puleo, 2011), el cual persigue «reafirma[r] el valor y la integridad particulares de cada ente vivo" (King, citada por Mies, Shiva, 1997, p. 26).

A mediados de la segunda década de este siglo, la politóloga iraní Nazanin Armanian opinaba que «el retroceso que han sufrido los derechos de la mujer a nivel global en las últimas tres décadas» tiene como causa "el agresivo avance del neoliberalismo militarizado», lo cual "nos invita a replantear [...] las prioridades del movimiento feminista a nivel mundial y regional» (2016b, párr. 1). Tiempo antes, a mediados de los ochenta, la pensadora Maria Mies ya admitía que «formular una perspectiva feminista de una sociedad futura es una tarea formidable» y que, frente a este reto, «no existe un epicentro teórico o ideológico en el movimiento de mujeres que pueda asumir la tarea de desarrollar una teoría, una estrategia y unas prácticas consistentes» (1986/2019, p. 375). A pesar de lo cual, se atrevía a esbozar algunas breves pinceladas de lo que, a su juicio, debieran constituir ejes nodales de una propuesta dirigida hacia un "concepto feminista de trabajo». Para ello se distanciaba de forma expresa del trabajo asalariado industrial y se remitía tanto al trabajo de las comunidades rurales no orientadas al mercado como, también, a otras labores muy feminizadas, como la maternidad misma. En ellos, la autora percibía que existía una

interacción entre el trabajo como necesidad y como carga, y del trabajo como origen de diversión y expresión personal. Podemos decir lo mismo del trabajo del artesano o el del trabajador involucrado en procesos de producción manuales, siempre que su trabajo no esté totalmente subsumido en las compulsiones del mercado. (Mies, 1986/2019, pp. 387-8).

Esta concepción del trabajo -donde este no se escinde con artificialidad del resto de la existencia, sino que la nutre e imbrica-, así como la producción directa de "vida o valores de uso", y no de bienes para el mercado, es lo que entendía la autora que puede convertir a una economía feminista en una economía "productora de vida». Sin embargo, para ello preconizaba el regreso a formas tradicionales o precapitalistas de vida, muy ruralizadas. En parte se inspiraba en la experiencia ancestral de las mujeres del Sur americano en sus comunidades originarias (en especial a las de origen precolonial), las cuales, aunque se habrían desenvuelto durante siglos en contextos de relaciones patriarcales, se inscribirían en un "patriarcado débil» que aún dejaría margen para un carácter genuino que permitiera su relativa evocación. Pero lo que nos interesa subrayar aquí es que recurría a una concepción de trabajo libre, dotado de sentido por sí mismo, como fundamento de una sociedad humanizada, superadora de los mecanismos letales propios, según afirmaba, tanto del patriarcado histórico como de su particular expresión capitalista. 
Se hace necesario, pues, a partir de estas premisas, explorar algunas vías por las que estos precedentes (aun teniendo en cuenta sus limitaciones históricas) pudieran llegar a alimentar una alternativa -social, económica, e incluso humanaviable. Para ello será necesario conectar, a su vez, con algunos precedentes teóricos que contribuyan a dar forma a dicha posible alternativa.

\section{EL TRABAJO LIBRE, VÍA DE SUPERACIÓN DE LA VALORACIÓN MERITOCRÁTICA}

Afirmaba Richard Sennett en El artesano que «la sociedad moderna tiende a dar particular importancia a las diferencias de habilidad: la "economía de las habilidades" intenta constantemente distinguir entre listos y tontos» (2009, p. 297). La forma que han tomado los procesos de trabajo en empresas punteras clave al socaire de la globalización privilegiaría el cambio continuo de actividad, la adquisición casi permanente de nuevas destrezas. Pero, como contrapartida, tiende a convertirlas en superficiales, impidiendo la profundización en problemas específicos y el desarrollo de capacidades propias. En definitiva, se premiaría la extensión frente al perfeccionamiento, y en función de estos parámetros se diferenciaría entre individuos más y menos capaces. No obstante, la introducción de tales dinámicas habría generado entre un «extenso grupo de individuos de clase media [...] la sensación de que su vida había quedado a la deriva» (Sennett, 2007, p. 14).

Tal consideración de la inteligencia no deja de tener, por supuesto, otras consecuencias. El autor, que se muestra muy crítico con el "paradigma Stanford-Binet», muy vigente durante el siglo xx para los test de inteligencia, afirma que, en las formas de medición del $\mathrm{Cl}$ presente en los mismos,

hinchando pequeñas diferencias de grado hasta producir grandes diferencias cualitativas se legitima el sistema de privilegio. En correspondencia, al asimilar la media a la mediocridad se legitima el desprecio, razón por la cual Gran Bretaña destina proporcionalmente más fondos a la educación de élite que a las escuelas técnicas y por la que Estados Unidos tiene tantas dificultades en encontrar aportaciones contributivas sin ánimo de lucro a las escuelas de formación profesional. (Sennett, 2009, pp. 349350).

Frente a esta «sucesión de proyectos o tareas» que se encontraría «demoliendo las carreras profesionales», él apuesta por lo que llama «trabajo artesano». Este acogería la más amplia gama de actividades, desde el trabajo manual especializado a otras tan variadas como la programación informática, el ejercicio de la medicina, la ejecución de un instrumento musical o la educación de los hijos. Incluso el ejercicio de la ciudadanía. Así, " “Artesanía” designa[ría] un impulso humano duradero 
y básico, el deseo de realizar bien una tarea, sin más» (Sennet, 2009, p. 21). Conduciría a la persecución de la calidad de lo que se realiza; pero, además, en tanto que invita a la permanente reflexión acerca del proceso mismo de trabajo y sobre el propio sujeto, constituye una vía para el autoconocimiento. En tanto que vinculado con lo más genuino en el ser humano, puede considerarse, junto con el juego (al que el autor de alguna manera asimila) como un modelo de realización libre, con hondas implicaciones personales y también sociales. Es por esta razón que «prácticamente todos los seres humanos pueden llegar a ser buenos artesanos» (p. 329). En palabras del educador John Dewey,

Tanto el trabajo como el juego son libres y tienen su motivación intrínseca, al margen de las falsas condiciones económicas que tienden a hacer del juego un estímulo ocioso para los sectores pudientes y del trabajo una tarea desagradable para los pobres. [...] se convierte en un trabajo coaccionado cuando sus efectos quedan al margen de la actividad, como un fin para el cual ésta sólo es un medio. El trabajo que se mantiene impregnado de juego es arte. (Dewey, Democracy and Education, citado por Sennett, 2009, p. 353).

Aunque Sennett advierte de los peligros propios del trabajo "artesano», este no se encontraría guiado de forma primordial por motivaciones extrínsecas y ajenas a él mismo, como el prestigio o el lucro. No quedaría, pues, atrapado en la escala de valorización/desvalorización permanente, nuclear en las realizaciones de las sociedades meritocráticas, donde se mide «el éxito de cada uno en función del nivel de fracaso del otro» o donde las relaciones "entre los seres humanos o entre categorías de seres humanos» toman la forma de la relación entre sujeto y objeto (Bauman, 2014, pp. 76 y 95). El trabajo "artesano», en cuanto dirigido por una vocación más genuina, se movería procurando ante todo el conocimiento ajustado de su objeto, de su naturaleza o características propias (sea un niño o niña, un violín o una célula), y no necesariamente su instrumentalización para el logro de un fin externo, que en ocasiones no tendría cabida alguna. El trabajo no se entendería como una relación de dominio, sino de descubrimiento de posibilidades por ambas partes. En este sentido puede decirse que es este tipo de trabajo el que posibilita la afirmación de la vida, aunque no sea él su única condición. Ello establece una conexión clave con el trabajo de las mujeres: en tanto que mucho más centrado en la vida humana y las relaciones socio-afectivas, se ha mantenido al margen de los mecanismos de valorización del capital (Carrasco, 2006b, p. 85; Piccio, 2001, pp. 15-21), cuya ley es la mercantilización de la vida. Esto lo convertiría en pieza importante en lo concerniente a la formulación de formas más auténticas de economía, trabajo y relaciones humanas en el contexto de un necesario "cambio de paradigma» (Amoroso et al., 2003, p. 10; Carrasco, 2013, pp. 40, 42). 
Ha sido E. F. Schumacher uno de los autores que más ha insistido en la necesidad de plantear un trabajo humanizado, dotado de auténtico sentido, para la superación de los males de la civilización industrial y su afán de crecimiento ilimitado. Una nota definitoria de este modelo social y económico vigente sería, precisamente, el de la negación de la creatividad humana en el trabajo; el hecho de que el propio ser humano se torne en un apéndice o elemento sujeto a el proceso de producción, negando así su libertad (hecho que el autor denosta como «crimen en contra de la humanidad»). El resultado inevitable sería "el escapismo o la agresión»; en otras palabras: el consumismo o la guerra. Así, unas sociedades que habrían convertido la "codicia» y la "envidia» en su leitmotiv, habrían despojado al ser humano de sabiduría. Pero sin ella el ser humano «se ve obligado a construir una economía monstruosa que destruye el mundo y a buscar afanosamente satisfacciones fantásticas» (Schumacher, 1983, pp. 36-39). Una de las vías a su juicio primordiales para recuperar esa inteligencia perdida es la de preguntarse por los auténticos fines del trabajo, que él sintetizaba de la manera que sigue:

1. Proporcionarnos bienes y servicios necesarios y útiles.

2.- Permitirnos a todos utilizar y con ello perfeccionar, como buenos administradores, nuestros talentos naturales.

3. - Hacerlo sirviendo a los demás y cooperando con ellos para liberarnos de nuestro innato egocentrismo. (Schumacher, 1983, 1980, p. 16).

Otros muchos han percibido las consecuencias devastadoras, a nivel personal y social, del trabajo alienado de los auténticos fines de la vida. Albert Camus, por ejemplo, lo comparó con el afán y la tarea absurda de Sísifo (1981, pp. 179-181). Pero tal vez lo más importante a resaltar aquí, dados los fines de este estudio, sean los beneficios de un trabajo que quepa considerar libre, a cuya mayor comprensión, vindicación y generalización pudiera contribuir, como queda dicho, la experiencia propia del trabajo de las mujeres.

En los años cincuenta del siglo pasado, el economista Galbraith localizó a una determinada fracción de la sociedad norteamericana, a la que denominó «Nueva Clase», que trabajaba ante todo por vocación. Aunque sus salarios solían ser altos, el autor resaltaba que «quienes desempeñan este tipo de trabajo confían en brindar lo mejor de sí mismos, sin tener en cuenta la compensación que reciban. Cualquier sugerencia en contrario les trastornaría» (1958/1985, p. 286). Es decir, que el carácter vocacional de sus ocupaciones dotaba a estas de un considerable margen de desinterés con relación a factores extrínsecos, como las retribuciones económicas. $Y$ hasta tal punto el autor detectaba en este tipo de actividades una oportunidad para la humanización de las sociedades industriales, para la elevación de sus niveles educativos y la calidad de vida en el trabajo, que sostuvo que «una expansión ulterior y rápida de esta clase debería ser uno de los objetivos 
más importantes y, quizá, después tan sólo de la misma supervivencia pacífica, el objetivo social más importante de la sociedad» (p. 288). Algo que estimaba ambicioso, pero factible.

Lo que señalaba Galbraith respecto al desinterés económico relativo que mostraban aquellos favorecidos con un trabajo motivador puede observarse en numerosas experiencias de trabajo vocacional. En ciertos casos, a veces conocidos, dicho trabajo se ha continuado desarrollando aun en condiciones que no compensan ya materialmente; esto es, en circunstancias en las cuales el ejercicio de dicha actividad implica un considerable sacrificio personal o familiar. Aunque a menudo desapercibido, resulta posible detectar un modelo de realización humana en el trabajo que se mantiene al margen de los mecanismos meritocráticos y de competencia habituales, si bien muchas veces de forma aleatoria y con limitaciones. Su raigambre en la vocación implica, además, un yo más rico, amplio y generoso, como observaba Dewey (1916/2004, pp. 292-295). El objetivo principal de este trabajo, pues, no sería el de recibir a la postre más de lo invertido (que es la fórmula clásica del capital), sino recibir lo justo o suficiente para estar en condiciones, ante todo, de poder seguir dando (Almansa Pérez, 2015). Aun sin ser conscientes de ello, y en condiciones muchas veces penosas, es lo que han estado realizando las mujeres a lo largo de buena parte de su historia.

Este tipo de trabajo requiere, por tanto, como cualquier otro, una retribución justa para restablecer las condiciones adecuadas y dignas de vida que permitan su continuidad. Su carácter vocacional, desinteresado en sus fines últimos, ha permitido en ocasiones emplear para él el término "gratuidad», aunque ello no signifique, insistimos, «trabajo gratis». Así lo expresaba uno de los más importantes teóricos de la llamada Economía de comunión:

La fuerza de muchas experiencias de economía social radica en el valor que dan a la gratuidad. Al nacer por "vocación», llevan el sabor específico de la gratuidad. Tal vez solamente lo que nace de una vocación interior pueda ser verdaderamente gratuito por ser verdaderamente libre. Efectivamente, sólo donde habita la libertad hay gratuidad, y sólo la gratuidad es verdaderamente libre. (Bruni, 2008, p. 60).

Un modelo de actividad, en definitiva, que conlleva modos específicos de vida alejados del afán instrumentalizador, del consumismo y del individualismo (ligados de forma indisoluble). En tanto que prescinde o se encuentra al margen de los mecanismos de competencia, resulta capaz de hacer del trabajo o del aprendizaje actividades colectivas, experiencias compartidas y no cotos cerrados donde unas partes se vuelven opacas a otras. Es en este sentido que Dewey, como otros autores, consideró que "la buena artesanía lleva implícito el socialismo» (citado por Sennett, 2009, p. 353). Puesto que su fin no es la afirmación de privilegios, ni dejar constancia de las supuestas habilidades de determinadas élites, 
no solo resulta ser un canal para el descubrimiento y desarrollo universal de habilidades, aptitudes y motivaciones, o para el desarrollo de proyectos colectivos no elitistas, sino que cabe también que se transforme en un revulsivo contra las desigualdades en la calidad de vida, expresión actual y pasada de las justificaciones meritocráticas.

Los llamados cuidados no son la única modalidad de actividad centrada (aunque de manera aún poco consciente) en la reproducción de la vida en un sentido amplio. Ocupaciones de cooperación desinteresada, de voluntariado, de realización de la propia labor o profesión sin expectativas volcadas en la promoción o el reconocimiento social externo, sino con el objetivo prioritario de hacer el propio trabajo bien hecho, por amor a su objeto, son ejemplos de lo mismo. Y muchos de ellos son desempeñados asimismo por mujeres, aunque esto sea visto, en ocasiones, como una "desventaja» por constituir un obstáculo en la carrera habitual de competencias (Heijstra, Einarsdóttir, Pétursdóttir, Steinpórsdóttir, 2017).

Es plausible que la delimitación de las características propias de un trabajo humanizador, a nivel personal y social, y en simbiosis armónica con la naturaleza, pueda otorgar contenido a la reivindicación feminista de poner «una vida que merezca ser vivida» en el centro (Pérez Orozco, 2015, p. 77). Semejante objetivo requeriría, no obstante, de una labor específica y exhaustiva de investigación, sistematización y concreción para tomar la forma de una alternativa coherente y viable. Asimismo, resulta evidente que debe conectarse, por todas las profundas implicaciones que conlleva, con otras esferas determinantes, desde la producción, el consumo, la propiedad o la división del trabajo, hasta la educación o la psicología. Las posibilidades que se abrirían con ello serían, seguramente, inmensas.

\section{CONCLUSIONES: LAS MUJERES COMO PARTE DE UN SUJETO POSIBLE DE CAMBIO SOCIAL}

Desde numerosos ámbitos se viene cuestionando, desde hace tiempo, un modelo social y económico que parece abocar al ahondamiento de las contradicciones de orden interno y con la naturaleza; un contexto en el que las mujeres, por sus situaciones de vulnerabilidad, resultan particularmente desfavorecidas. La búsqueda de alternativas, de vías de superación de la encrucijada actual, resulta primordial, y así viene haciéndose desde diversas instancias (Pieiller, 2020). En ellas se van imponiendo compresiones de lo humano alejadas de las explicaciones de competencia y más cercanas a patrones de igualdad, colaboración e interdependencia.

En el presente estudio se ha pretendido contribuir a esta labor a través de la investigación de las fuentes de legitimación $-y$, por tanto, de sostenimiento- de la desigualdad social, y sus posibilidades actuales de superación por parte de un 
colectivo aún sometido: las mujeres. A través de diversos ejemplos, se ha constatado que, desde los inicios de las sociedades históricas, los grupos dominantes justificaron de forma invariable su propia situación de preeminencia por la posesión de determinados atributos o su éxito en empeños de especial valía. Unos y otros se consideraron méritos inherentes a la clase o grupo de poder correspondiente (especialmente de sus varones), si bien sus contenidos y formas concretas pudieron sufrir modificaciones con el tiempo.

La era contemporánea -marcada con el sello del triunfo de la burguesía sobre el orden estamental- ha sido juzgada como la meritocrática por excelencia porque los límites entre clases se hacen flexibles y puede ascenderse en la escala social por logros individuales con mayor facilidad que antes. No solo eso: es que esta extendida dinámica competitiva se convierte en un desiderátum, y, por consiguiente, en la nueva justificación predominante de las diferencias económicas o de disponibilidad sobre bienes y recursos esenciales.

Los reconocimientos universales de derechos individuales incorporarán de forma progresiva a las mujeres y a otros colectivos excluidos a la carrera por el mérito; y ello se traducirá en cotas de participación e igualdad inéditas en épocas anteriores en los países occidentales, que, además, se han ido extendiendo de manera paulatina, aunque muy desigual, a otras regiones del mundo. Sin embargo, persisten hoy -también en las naciones del capitalismo rico y en sus periferias-importantes, cuando no lacerantes desigualdades y violencias que afectan muy especialmente a las mujeres. La presión sobre ellas, y sobre las más explotadas y desposeídas en particular, se recrudece, además, en momentos muy claros de rebrote de un nuevo elitismo que va de la mano del acrecentamiento de las desigualdades, aunque este fenómeno afecte a sectores relativamente amplios en determinados países. Por otra parte, como queda visto, el acceso de muchas mujeres a puestos influyentes o de poder se ha producido en correspondencia con situaciones previas de preeminencia social. Sin embargo, una inmensa mayoría -y en las zonas capitalistas desarrolladas aún en proporciones considerables- continúa inmersa en trabajos que se encuentran, de hecho, en el reverso de la competición jerarquizadora. Aunque en numerosas ocasiones de manera involuntaria, poco consciente o en condiciones desfavorables, estas actividades se encuentran al margen del interés rentabilizador: esto es, no persiguen, de forma prioritaria, la instrumentalización de otros sujetos o de la naturaleza, sino su cuidado o reproducción.

En las actuales circunstancias de deterioro económico, social y ecológico, cobra creciente vigencia que el paradigma que denominamos 'competitivo-meritocrático', presente desde el advenimiento de la contemporaneidad, se ha basado sobre la instrumentalización mercantilizada masiva de la naturaleza y de la fuerza de trabajo, tomados como meros factores de producción y consumo. Así lo pusieron de manifiesto Marx o Polanyi en su momento y vienen haciéndolo otros 
muchos desde entonces. Dadas las cotas de desigualdad, explotación, despojo y degradación humana y natural generadas con él, no parece que pueda continuar siendo sostenido (al menos en las condiciones actuales) durante mucho tiempo. En una situación semejante, parece crucial el replanteamiento de la cuestión del trabajo como clave en una organización social no fragmentada -donde unos seres humanos no se "deduzcan» de los requerimientos o intereses de otros-, compatible y afirmadora de los ritmos naturales y de la legítima singularidad humana, personal y colectiva. De alguna manera viene emergiendo, aunque de forma aún dispersa y falta de concreción suficiente, la exigencia de un trabajo humanizador por sí mismo, que permita trascender el objetivo central de la actividad anti-económica actual (en tanto que no permite reproducir la vida en condiciones ni óptimas ni sustentables), esto es, la valorización permanente del capital (Riechmann, 1998, pp. 18, 27).

Las corrientes teóricas del ecofeminismo, la economía feminista o el ecosocialismo han venido tomando como referente para ello el trabajo de las mujeres. Esto se hace posible desde el momento en que no se concibe su emancipación -ni la de la humanidad en general- desde el prisma de su mera integración en los mecanismos de propios de la sociedad meritocrática. Es por ello que resultaría cuestionable un feminismo reivindicado como elitista (Valcárcel, 1997, p. 82). Si, por el contrario, se profundiza en una senda de comprensión de que son estos mecanismos los que se encuentran en la base de legitimación de cualquier situación de desigualdad (implique o no esta derechos formales reconocidos), sempiterna fuente de privilegios, cabe aumentar las posibilidades de construcción de alternativas a las graves situaciones que hoy se padecen.

Tomar conciencia de la relevancia y significación del modelo de trabajo que ha sido llamado, según circunstancias y momentos, "artesano», "libre», "autorrealizado", "bueno», o con otros calificativos, puede resultar de gran importancia en un contexto de planteamiento de proyectos sociales de superación de las desigualdades sociales. Con todo, quedarían pendientes cuestiones completamente determinantes, tales como los fines prioritarios y legítimos, sociales y personales, a cubrir por el trabajo y la producción, o la configuración de la división del trabajo a muchos niveles. No obstante, investigar sobre la naturaleza, las formas y posibilidades de desarrollo del trabajo des-interesado, según lo expuesto, sería un paso importante en este sentido. La experiencia de las mujeres, en su larga trayectoria en ocupaciones que se han encontrado al margen de la competencia meritocrática, y en su papel central en los mecanismos de reproducción y recreación de la vida (biológica, afectiva, psicológica o cultural), se manifestaría de gran significación en la constitución de un hipotético nuevo sujeto social que enarbole este trabajo libre como prioridad. Precisamente por vocacional y desinteresado, un trabajo no concebido ya como un lujo, privilegio o actividad subsidiaria o marginal, sino como necesario en tanto que inherente al orden propio de la vida. 


\section{REFERENCIAS BIBLIOGRÁFICAS}

AA. VV. (2006). Las mujeres en la prehistoria. València: Museu de Prehistòria de València.

Aguado, A. (2003). Género y ciudadanía en la formación de la sociedad burguesa. Arenal: Revista de historia de mujeres, 10(1), pp. 61-79.

Aguado, A. (2005). Ciudadanía, mujeres y democracia. Historia constitucional: Revista Electrónica de Historia Constitucional, (6), pp. 11-27. https://dialnet. unirioja.es/servlet/articulo?codigo=1254727.

Almansa, R. M. (2015). Relaciones entre ser humano, trabajo y naturaleza desde una perspectiva histórico-antropológica. En L. Mora, L. y J. Escribano (Eds.), Ecología del Trabajo: El trabajo que sostiene la vida (pp. 103-132). Albacete: Bomarzo.

Almansa, R. M. (2019). El populismo de extrema derecha en los Estados Unidos de la era Trump: De la democracia «sin rostro» a la reacción identitaria. Anales de la Cátedra Francisco Suárez, (53), pp. 157-181. https://doi.org/10.30827/ACFS. v53i0.7947.

Alvaredo, F.; Chancel, L.; Piketty, T.; Sáez, E.; Zucma, G. (Coords.) (2017). Informe sobre la Desigualdad Global de 2018. (Resumen ejecutivo). Berlín: World Inequality Lab. https://wir2018.wid.world/files/download/wir2018-summaryspanish.pdf.

Amorós, C. (2008). Mujeres e imaginarios de la globalización: reflexiones para una agenda teórica global del feminismo. Rosario: Homo Sapiens.

Amoroso, M. I., Bosch, A., Carrasco, C., Fernández, H., Moreno, N. (2003). Malabaristas de la vida. Mujeres, tiempos y trabajos. Barcelona: Icaria.

Andrzejewski, C. (2017). La invisible penosidad del trabajo femenino. Le Monde Diplomatique en español, (266), pp. 18-19.

Armanian, N. (2016a, 3 de octubre). El triunfo de Hilary Clinton no es el triunfo de la mujer. Público. http://blogs.publico.es/puntoyseguido/3568/el-triunfo-dehillary-clinton-no-es-el-triunfo-de-la-mujer. 
Armanian, N. (2016b, 5 de noviembre). La mujer en diez noticias breves. Público. http://blogs.publico.es/puntoyseguido/3604/la-mujer-en-diez-noticiasbreves/.

Arrow, K. J., Bowles, S., Durlauf, S. (Eds.). (2000). Meritocracyand economic inequality. Princeton:PrincetonUniversityPress.https://doi.org/10.1515/9780691190334.

Ballarín, P., Birriel, M. M., Martínez, C., Ortiz, T. (2000). Las mujeres y la historia de Europa. En P. Ballarín (Coord.), Las mujeres en Europa. Convergencias y diversidades (pp. 11-56). Granada: Universidad de Granada.

Bardi, Ugo (2014). Los límites del crecimiento retomados. Madrid: Catarata.

Bauman, Z. (2003). Comunidad: en busca de seguridad en un mundo hostil. Madrid: Siglo XXI.

Bauman, Z. (2014). ¿La riqueza de unos pocos nos beneficia a todos? Barcelona: Paidós.

Beaugé, F. (2016). No todas las estadounidenses se llaman Hillary Clinton. Le Monde Diplomatique en español, (253), pp. 6-7.

Beauvoir, S. de (1949/2005). El segundo sexo. Madrid: Cátedra.

Beck, U. (2000). Un nuevo mundo feliz. La precariedad del trabajo en la era de la globalización. Barcelona: Paidós.

Beck, U., Beck-Gernsheim, E. (2003). La individualización. El individualismo institucionalizado y sus consecuencias sociales y políticas. Barcelona: Paidós.

Bensaïd, D. (2010). Cambiar el mundo. Madrid: Los Libros de la Catarata, Diario Público.

Bericat, E., Sánchez, E. (2008). Balance de la desigualdad de género en España: un sistema de indicadores sociales, (Informe Núm. 23. Colección Actualidad. Centro de Estudios Andaluces), pp. 1-29. https://www.centrodeestudiosandaluces. es/publicaciones/n-23-balance-de-la-desigualdad-de-genero-en-espana-unsistema-de-indicadores-sociales. 
Bernal, A. F. (2014), Las mujeres y el poder político: una investidura incompleta (Tesis de doctorado). Universidad Autónoma de Barcelona. https://www.tdx. cat/bitstream/handle/10803/285772/afbo1de1.pdf?sequence=1.

Bourdieu, P. (2000/1998). La dominación masculina. Madrid: Anagrama.

Brooks, N., Mcquaig, L. (2014). El problema de los super-millonarios. Cómo se han apropiado del mundo los super-ricos y cómo podemos recuperarlo. Madrid: Capitán Swing.

Bruni, L. (2008). El precio de la gratuidad. Madrid: Ciudad Nueva.

Caballero, M. (2016). ¿Hay mujeres más allá del feminismo? De la lucha por la igualdad al transhumanismo/posthumanismo. Arbor Ciencia, Pensamiento y Cultura, 192 (778), pp. 1-6. https://dx.doi.org/10.3989/arbor.2016.i778.

Camus, A. (1981). El mito de Sísifo. Ensayos (pp. 179-193). Madrid: Aguilar.

Capel, R. M. (2014). ¿Es el feminismo una utopía? Crítica, (991-992), pp. 69-73. https://doi.org/10.1016/j.crad.2014.07.005.

Carrasco, C., Borderías, C., Torns, T. (2011). El trabajo de cuidados. Historia, teoría y política. Madrid: CIP-Ecosocial, La Catarata.

Carrasco, C. (2006a). La economía feminista: una apuesta por otra economía. En M. J. Vara (Coord.), Estudios sobre género y economía (pp. 29-62). Madrid: Akal.

Carrasco, C. (2006b). Trabajos, cuidados y sostenibilidad: un desafío para el siglo XXI. En El trabajo en el siglo XXI: perspectivas de futuro (pp. 81-110). (XXIII Cursos de Verano en San Sebastián. XVI Cursos Europeos-UPV/EHU 2004). San Sebastián: Ararteko.

Carrasco, C. (2013). El cuidado como eje vertebrador de una nueva economía. Cuadernos de relaciones laborales, 31(1), pp. 39-56. https://doi.org/10.5209/ rev_CRLA.2013.v31.n1.41627.

Cembranos, F., Herrero, Y., Pascual, M., Hernández, A., Morán, C. et al. (2011). La centralidad de los cuidados, las mujeres y la sostenibilidad. En Y. Herrero, F. Cembranos y M. Pascual (Coords.), Cambiar las gafas para cambiar el mundo. Una nueva cultura de la sostenibilidad (pp. 181-2011). Madrid: Ecologistas en acción. 
Choma, R. (2014, 9 de enero). Millionaires' Club: For First Time, Most Lawmakers are Worth \$1 Million-Plus. OpenSecrets.org. https://www.opensecrets.org/ news/2014/01/millionaires-club-for-first-time-most-lawmakers-are-worth-1million-plus/.

Cobo, R. (2011). ¿Educación para la libertad?: las mujeres ante la reacción patriarcal. Revista interuniversitaria de formación del profesorado, (71), pp. 63-72.

Cobo, R. (2016). Globalización, desigualdades y género ¿Son inevitables? Gaceta sindical: reflexión y debate, (26), pp. 141-153.

Cohen, C. (2011). La mujer de los orígenes: imágenes de la mujer en la prehistoria occidental. Madrid: Cátedra.

Comín, A. (2011). El capitalismo y las teorías de la justicia contemporáneas. En A. Comín y L. Gervasoni (Coords.). Democracia económica. Hacia una alternativa al capitalismo (pp. 85-141). Barcelona: Icaria.

Confessore, N., Cohen, S., Yourish, K. (2015, 10 de octubre). The Families Funding the 2016 Presidential Election. The New York Times. https://www.nytimes. com/interactive/2015/10/11/us/politics/2016-presidential-election-superpac-donors.html.

Cooper, J. P. (1976). Introducción general. En La decadencia española y la Guerra de los Treinta Años. 1610-1648-59. En J. Reglá (Dir.), Historia del Mundo Moderno (Vol. IV, pp. 1-44). Cambridge, Barcelona: Cambridge University Press, Sopena.

Cordua, C. (1989). El mundo ético. Ensayos sobre la esfera del hombre en la filosofía de Hegel. Barcelona: Anthropos.

Crouch, C. (2004). Posdemocracia. Barcelona: Taurus.

Currid-Halkett, E. (2017). The Sum of Small Things: A Theory of the Aspirational Class. Princeton:PrincetonUniversityPress. https://doi.org/10.1515/9781400884698.

Daguerre, A. (2005). La culpabilización de los desempleados en Estados Unidos y en Europa. Le Monde Diplomatique en español, (116), pp. 6-7.

Delibes, G., Fernández-Miranda, M. (1993). Los orígenes de la civilización. El Calcolítico en el Viejo Mundo. Madrid: Síntesis. 
Dewey, J. (1916/2004). Democracia y educación. Una introducción a la filosofía de la educación. Madrid: Morata.

Domínguez, M. (2013). Introducción. En V. Pareto, Forma y equilibrio sociales (Selección) (pp. 9-118). Madrid: Minerva, Biblioteca Nueva.

Durán, M. A. (2008). Cambios sociales, empleo y trabajo no remunerado. En R. M. Capel (Dir.). Cien años trabajando por la igualdad (pp. 223-235). Madrid: Fundación Francisco Largo Caballero, Unión General de Trabajadores, Instituto de la Mujer.

Federici, S. (2010). Calibán y la bruja. Mujeres, cuerpo y acumulación originaria. Madrid: Traficantes de Sueños.

Fernández, A. (2015) (coord.). Prehistoria II. Las sociedades metalúrgicas. Madrid: Editorial Ramón Areces.

Fernández Buey, F. (2009), Crisis de civilización. Papeles de relaciones ecosociales y cambio global, (105), pp. 41-51.

Fernández Durán, R. (2011). El Antropoceno. La crisis ecológica se hace global. Barcelona: Virus.

Flecha, C. (2004). El papel humanizador desempeñado por las mujeres. Humanismo y trabajo social, (3), pp. 23-46.

Fradera, J. M., Millán, J. (Eds.). (2000). Las burguesías europeas del siglo XIX: sociedad civil, política y cultura. Madrid, Valencia: Biblioteca Nueva, Universitat de Valencia.

Fraser, N. (2015). Fortunas del feminismo. Del capitalismo gestionado por el Estado a la crisis neoliberal. Quito, Madrid: Instituto de Altos Estudios Nacionales del Ecuador, Traficantes de Sueños.

Fraser, N. (2017, 12 de enero). El final del neoliberalismo 'progresista'. Sin Permiso. http://www.sinpermiso.info/textos/el-final-del-neoliberalismo-progresista.

Friedman, M., Friedman, R. (1988/1980). Libertad de elegir. Barcelona: Orbis.

Galbraith, J. K. (1958/1985). La sociedad opulenta. Barcelona: Planeta. 
Gaudichaud, F. (2019). Marea feminista, también en Chile. Las mujeres, las primeras víctimas del ultracapitalismo andino. Le Monde diplomatique en español, (283), pp. 16-17.

George, S. (2015). Los usurpadores. Cómo las empresas transnacionales toman el poder. Barcelona: Icaria.

Godelier, M. (1981). The origins of Male Domination. New Left Review, (127), pp. 3-17.

Gorz, A. (1997). Metamorfosis del trabajo. Búsqueda del sentido. Crítica de la razón económica. Madrid: Sistema.

Gschnitzer, F. (2005). Historia social de Grecia. Desde el período micénico al final de la época clásica. Madrid: Akal.

Halimi, S. (2017). La trampa del 99\%. Le Monde Diplomatique en español, (262), p. 32.

Hardoon, D., Ayele, S., Fuentes-Nieva, R. (2016, 8 de enero). An economy of the one percent. How privilege and power in the economy drive extreme inequality and how this can be stopped. Oxfam. https://www.oxfam.org/en/research/ economy-1. https://doi.org/10.21201/2016.592643.

Hawkins, D. (2018, 27 de febrero), Wealth of Congress: Richer Than Ever, but Mostly at the Very Top. Roll Call. https://www.rollcall.com/news/hawkings/congressricher-ever-mostly-top.

Heijstra, T. M., Einarsdóttir, P., Pétursdóttir, G. M., Steinpórsdóttir, F. S. (2017). Testing the concept of academic housework in a European setting: Part of academic career-making or gendered barrier to the top? European Educational Research Journal, 16(2-3), 200-214. https://doi.org/10.1177/1474904116668884.

Herrero, Y. (2010). Cuidar: una práctica política anticapitalista y antipatriarcal. En C. Taibo (Dir.), Decrecimientos: sobre lo que hay que cambiar en la vida cotidiana (pp. 17-31). Madrid: Los Libros de la Catarata.

Hinkelammert, F. J., Duchrow, U. (2004). La vida o el capital. Alternativas a la dictadura global de la propiedad. México: Dríada.

Hobsbawm, E. (2011a). La era de la revolución. 1798-1848. Barcelona: Crítica. 
Hobsbawm, E. (2011b). La era del capital. 1848-1875. Barcelona: Crítica.

Hobsbawm, E. (2011b). La era del imperio. 1875-1914. Barcelona: Crítica.

Hochschild, A. R. (2016). Strangers in their Own Land. Anger and Mourning on the American Right. A journey to the Heart of Our Political Divide. New York: The New Press.

Jaeger, W. (1933, 1936/1962). Paideia: los ideales de la cultura griega. México: Fondo de Cultura Económica.

Jones, O. (2015). El stablishment: la casta al desnudo. Barcelona: Seix Barral.

Jutglar, A. (1999). El mundo del feudalismo. En F. Navarro (Dir.). La Edad Media. En Historia Universal Salvat (Vol. 9, pp. 21-42). Barcelona: Salvat.

Kaipper, M. (2014, 15 de diciembre). Brasil: un país con mayoría de mujeres y gobernado por hombres. El País. http://internacional.elpais.com/ internacional/2014/12/15/actualidad/1418673364_206261.html.

Kamen, H. (1984). European society. 1500-1700. Londres, Nueva York: Routledge.

Kelly, J. (1984). Women, History and Theory. Chicago: University of Chicago Press.

Kocka, J. (2000). Burguesía y sociedad burguesa en el siglo XIX. Modelos europeos y peculiaridades alemanas. En J. M. Fradera y J. Millán (Eds.). Las burguesías europeas del siglo XIX: sociedad civil, política y cultura (pp. 21-83). Madrid, Valencia: Biblioteca Nueva, Universitat de Valéncia.

Krugman, P. (2008). Después de Bush. El fin de los «neocons» y la hora de los demócratas. Barcelona: Crítica.

Lambert, R. (2018). ¿Es Brasil fascista? Las razones de un vuelco. Le Monde Diplomatique en español, (277), p. 8.

Lasch, C. (1996). La rebelión de las élites y la traición a la democracia. Barcelona: Paidós.

Lerner, G. (1990): La creación del patriarcado. Barcelona: Crítica. 
Mariette, M. (2019). Evo Morales, las políticas sociales y el consumismo. Le Monde Diplomatique en español, (287), pp. 10-12.

Marrou, H. I. (1948/1985). Historia de la educación en la Antigüedad, Madrid: Akal.

Martino, F. de (1985). Historia económica de la Roma antigua. I. Madrid: Akal.

Marx, K. (1844/1970). Manuscritos: Economía y filosofía. Madrid: Alianza.

Mcchesney, R. W., y Nichols, J. (2013). Dollarocracy: How the Money and Media Election Complex is Destroying America. New York: Nation Books.

Meadows, D. H., Meadows, D. L., Randers, J., y Behrens, W. (1972). Los límites del crecimiento: informe al Club de Roma sobre el predicamento de la Humanidad. México: Fondo de Cultura Económica.

Mellor, Mary (1996). Feminismo y ecología. México: Siglo XXI.

Mies, M. (1986/2019). Patriarcado y acumulación a escala mundial. Madrid: Traficantes de Sueños. https://www.traficantes.net/sites/default/files/pdfs/ map53_mies_web_2.pdf.

Mies, M. (1997). El mito de la recuperación del retraso en el desarrollo. En M. Mies y V. Shiva, Ecofeminismo (pp. 121-140). Barcelona: Icaria.

Mies, M., y Shiva, V. (1997). Ecofeminismo. Barcelona: Icaria.

Mises, L. Von (1927/1994). Liberalismo. Barcelona: Planeta-Agostini.

Mitre, E. (1983). Historia de la Edad Media. I. Occidente. Madrid: Alhambra Universidad.

Mora, L., Escribano, J. (2015). (Eds.). Ecología del trabajo. El trabajo que sostiene la vida. Albacete: Bomarzo.

Musso, P. (2019). La era del Estado-empresa. La política despolitizada. Le Monde diplomatique en español, (283), p. 3.

Muvuca Popular (2019, 18 de marzo). Bolsonaro adota meritocracia e acaba com privilégios do serviço público. Muvuca Popular. https://www.muvucapopular. 
com.br/politica/bolsonaro-adota-meritocracia-e-acaba-com-privilegios-doservico-publico/25265.

Nagle, A. (2017). 'Ese monstruo anónimo, el hombre de la calle'. Le Monde Diplomatique en español, (258), pp. 1, 3.

Naredo, J. M. (2006). Raíces económicas del deterioro ecológico y social: más allá de los dogmas. Madrid: Siglo XXI.

Nash, M. (2004). Mujeres en el mundo. Historia, retos y movimientos. Madrid: Alianza.

Nielfa, G. (1995). La revolución liberal desde la perspectiva del género. Ayer, (17), pp. 103-120. https://doi.org/10.2307/j.ctv512s0g.4.

Nielfa, G. (1999). ¿El siglo de las mujeres? Cuadernos de historia contemporánea, (21), pp. 63-82.

Observatorio Internacional de la Crisis, Piqueras, A., y Dierckxsens, W. (eds.) (2011), El colapso de la globalización. La Humanidad frente a la Gran Transición. Mataró (Barcelona): El Viejo Topo.

Organización Internacional del Trabajo (OIT) (2017). Estimaciones mundiales sobre la esclavitud moderna: Trabajo forzoso y matrimonio forzoso. OIT. Ginebra: Organización Internacional del Trabajo, Walk Free Foundation. https://www.ilo. org/wcmsp5/groups/public/@dgreports/@dcomm/documents/publication/ wcms_651915.pdf.

Organización Internacional del Trabajo (OIT) (2018). Perspectivas sociales y del empleo en el mundo: Avance global sobre las tendencias del empleo femenino 2018. OIT. Ginebra: Organización Internacional del Trabajo. https:// www.ilo.org/global/research/global-reports/weso/trends-for-women2018/ WCMS_619603/lang--es/index.htm.

Organización Internacional del Trabajo (OIT) (2019). Informe Mundial sobre Salarios 2018/19. ¿Qué hay detrás de la brecha salarial de género? OIT. Ginebra: Organización Internacional del Trabajo. https://www.ilo.org/global/ publications/books/WCMS_712957/lang--es/index.htm. 
Onu Mujeres (2019, junio). Hechos y cifras: liderazgo y participación política. Onu Mujeres. http://www.unwomen.org/es/what-we-do/leadership-and-politicalparticipation/facts-and-figures.

Oualalou, L. (2012). Lo que cambia para las mujeres. En Latinoamérica, progresos políticos y conservadurismo de la sociedad. Le Monde Diplomatique en español, (195), pp. 18-19.

Pascual, M. (2010). Las mujeres, protagonistas de la sostenibilidad. En AA. VV., Claves del ecologismo social (pp. 175-182). Madrid: Ecologistas en Acción.

Pérez Orozco, A. (2006). Perspectivas feministas en torno a la economía: el caso de los cuidados. Madrid: Consejo Económico y Social.

Pérez Orozco, A. (2014). Subversión feminista de la economía. Madrid: Traficantes de Sueños.

Pérez Orozco, A. (2015). La sostenibilidad de la vida en el centro... ¿Y eso qué significa? En L. Mora y J. Escribano (Eds.), Ecología del trabajo. El trabajo que sostiene la vida (pp. 71-100). Albacete: Bomarzo.

Phillips, A. (1996). ¿Deben las feministas abandonar la democracia liberal? En C. Castells (Comp.), Perspectivas feministas en teoría política (pp. 79-97). Barcelona: Paidós.

Piccio, A. (2001). Un enfoque macroeconómico 'ampliado' de las condiciones de vida. En C. Carrasco (Ed.). Tiempos, trabajo y género (pp. 15-37). Barcelona: Universitat de Barcelona.

Pieiller, E. (2020). Reinventar la humanidad... Hacia un futuro en común. Le Monde Diplomatique en español, (294), p. 10.

Piketty, T. (2014). El capital en el siglo XXI. Madrid: Fondo de Cultura Económica.

Piketty, T. (2015). La economía de las desigualdades. Barcelona: Anagrama.

Polanyi, K. (1957/2003). La gran transformación. Los orígenes políticos y económicos de nuestro tiempo. México: Fondo de Cultura Económica.

Puleo, A. (2011). Ecofeminismo para otro mundo posible. Madrid, Valencia: Cátedra, Universitat de València, Instituto de la Mujer. 
Raim, L. (2018). Zumos 'detox' y 'cardio training', el nuevo espíritu de la burguesía. Le Monde Diplomatique en español, (274), pp. 22-23.

Rawls, J. (1995). Teoría de la justicia. México: Fondo de Cultura Económica.

Reeves, R. V. (2017). Clase sin riesgos. Le Monde Diplomatique en español, (264), p. 32.

Rey, O. (1992). Poder y privilegios en la Europa del siglo XVIII. Madrid: Síntesis.

Riechmann, J. (1998). Trabajo y medio ambiente en la era de la crisis ecológica. En F. Fernández Buey y J. Riechmann (Eds.), Trabajar sin destruir. Sobre trabajadores, sindicatos y ecologismo. Madrid: HOAC.

Riechmann, J. (Ed.). (2013). iPeligro! Hombres trabajando. El trabajo en la era de la crisis ecológico-social. Madrid: Catarata.

Robin, L., Sörlin, S., y Warde, P. (Eds.). (2013). The Future of Nature: Documents of Global Change. Yale: Yale University Press.

Robinson, W. I. (2014). Una teoría sobre el capitalismo global. Producción, clase y Estado en un mundo transnacional. México D.F.: Siglo XXI.

Roldán, J. M. (1981). Historia de Roma. I. La República Romana. Madrid: Cátedra.

Schumacher, E. F. (1980). El buen trabajo. Madrid: Debate.

Schumacher, E. F. (1983). Lo pequeño es hermoso. Barcelona: Orbis.

Segato, R. L. (2016). La guerra contra las mujeres. Madrid: Traficantes de Sueños.

Sempere, J. (2008). Mejor con menos. Necesidades, explosión consumista y crisis ecológica. Barcelona: Crítica.

Sève, L. (2011). Salvar el género humano, no únicamente el planeta. La causa ecológica y la causa antropológica. Le Monde Diplomatique en español, (194), pp. 16-17.

Sennett, R. (2007). La cultura del nuevo capitalismo. Barcelona: Anagrama.

Sennett, R. (2009). El artesano. Barcelona: Anagrama. 
Spire, A., Hugrée; C., Penissat, E. (2017). La metamorfosis de las clases populares. Cambios en la estructura social europea. Le Monde Diplomatique en español, (260), p. 24.

Stiglitz, J. (2015). La Gran Brecha. Madrid: Taurus.

Thompson, E. P. (1963/2012). La formación de la clase obrera en Inglaterra. Madrid: Capitán Swing.

Tenenti, A. (1997/2011). La Edad Moderna. XVI-XVIII. Barcelona: Crítica.

Todd, E. (1999). La ilusión económica: ensayo sobre el estancamiento de las sociedades desarrolladas. Madrid: Taurus.

Todd, E. (2010). Después de la democracia. Madrid: Akal.

Valcárcel, A. (1997). La política de las mujeres. Madrid: Cátedra.

Vara, M. J. (2006). Empleo femenino en las cadenas de producción global. En M. J. Vara (Coord.), Estudios sobre género y economía (pp. 63-82). Madrid: Akal.

Vigna, A. (2017). En Brasil, la crisis enardece a las derechas. Le Monde Diplomatique en español, (266), pp. 1, 17.

Veblen, T. (1899/1974). Teoría de la clase ociosa. México: Fondo de Cultura Económica.

Villota, P. (2004). Globalización, desigualdad y ciudadanía social desde la perspectiva de género. En P. Villota (Ed.), Globalización y desigualdad de género (pp. 131160). Madrid: Síntesis.

Young, M. (1958/1961). The Rise of the Meritocracy: an essay on education and equality. Middlesex (England): Penguin Books.

Wirth, L. (2002). Romper el techo de cristal. Las mujeres en puestos de dirección, Madrid: Ministerio de Trabajo y Asuntos Sociales, Organización Internacional del Trabajo.

Women of the World Global Platform (s. f.). http://www.womenworldplatform.com. 
Página intencionadamente en blanco. 